\title{
From vectors to waves and streams: An alternative approach to semantic maps ${ }^{1}$
}

\author{
Alexander Andrason \\ Department of African Languages, Stellenbosch University, South Africa \\ E-mail: andrason@sun.ac.za
}

\begin{abstract}
This article designs a method of improving traditional, qualitative semantic maps based on grammaticalisation paths, by including both quantitative data (frequency) and information concerning a gram's environment (the relation to the other maps). The incorporation of qualitative evidence transforms vectored maps into waves, while the introduction of the contextual factor combines waves organised along the same grammaticalisation template into a stream. The structure of a wave delivers, in turn, the statistical prototypicality of a gram (i.e. the prototypicality that is conditioned by the gram's own wave), whereas the structure of the stream yields product prototypicality (i.e. the prototypicality that is a combination of the gram's wave and the other waves of the stream). It is additionally hypothesised that the product prototypicality may be an overt indicator of the psychological perception of the grams by speakers.
\end{abstract}

Keywords: cognitive linguistics, semantic maps, grammaticalisation, verbal system

\section{Semantic maps and their shortcomings ${ }^{2}$}

During the last 30 years, semantic maps have gained recognition in the modeling of semantics of grammatical entities. Nowadays, they constitute one of the most common techniques used for the description and analysis of meanings in cognitive linguistics, linguistic typology and grammaticalisation studies (Haspelmath 1997, 2003; Croft 2001, 2003; De Haan 2004, 2010; Zwarts 2010; Narrog and Van de Auwera 2011). The classical approach to maps, codified in an article written by Martin Haspelmath in 2003 and in a book authored, the same year, by William

\footnotetext{
${ }^{1}$ The present paper emerged as a by-product of two studies I conducted previously. One was dedicated to the application of an affordances framework (or an affordances perspective) to grammaticalisation theory (cf. Andrason and Visser 2015) and the other concerned the analysis of the verbal system of Mandinka and Biblical Hebrew (Andrason 2015a, 2016a, 2016b, forthcoming). Although the present article constitutes an original work, by continuing and refining the ideas discussed in my previous publications, it shares, to an extent, the research scope with the above-mentioned papers.

${ }^{2}$ This introductory, theoretical section draws from my $\mathrm{PhD}$ dissertation Complex system of Complex Predicates Tense, Taxis, Aspect and Mood in Basse Mandinka from a Grammaticalisation and Cognitive Perspective (Andrason 2016a).
} 
Croft can be summarised in the following general terms: A semantic map represents the meaning of a form as a polysemous network of interrelated senses.

The origin of semantic maps is linked to the fact that grammatical and lexical units (for instance, constructions, words or morphemes) are inherently polysemous and that this polysemy is coherent. Firstly, although the precise number of senses that can be conveyed by a form - and, thus, the composition and extension of a map - depends on the granularity adopted by a researcher, ${ }^{3}$ multiple empirical studies have demonstrated that polysemy can be viewed as a norm in languages of the world (Cuykens and Zawada 2001a, 2001b; Croft and Cruse 2004; Evans and Tyler 2004; Evans 2006; Taylor 2006; Evans and Green 2006: 169; Falkum and Vicente 2015). It is necessitated by the very process of language change and grammaticalisation (Heine 1997; Bybee 2010).

Secondly, senses that can be expressed by a construction are related to each other, forming a coherent whole. This inherent cohesion is referred to as the relatedness principle and is, itself, granted by two facts. On the one hand, senses are connected because they arise due to human cognitive mechanisms, being derived by means of metaphor, image-schema process, metonymy, analogy and abduction (Andersen 1973; Antilla 1989; Sweetser 1990; Lichtenberk 1991; Traugott and König 1991; Bybee, Perkins and Pagliuca 1994; Heine 1997; Radden and Kövecses 1999; Panther and Radden 1999; Croft and Cruse 2004; Steen 2007; Yu 2008, 2009; CarstairsMcCarthy 2010; Geeraerts 2010). On the other hand, they are connected because they constitute a temporally sequential chain of predecessors and successors - one sense constitutes a chronological source of the other. As a result, the unity of a polysemous set is both conceptual and historical (Lakoff 1987; Gibbs 1994; Heine, Claudi and Hünnemeyer 1991; IbarretxeAntuñano 1999, Taylor 2002; Tuggy 2003; Janssen 2003; Haspelmath 2003; Croft 2003; Cruse 2004; Evans and Green 2006; Lewandowska-Tomaszczyk 2007; Nikiforidou 2009; Bybee 2010; De Haan 2010; Van der Auwera and Gast 2011; Munné 2013; Massip-Bonet 2013). To put it simply, there is "a motivated [linear or multi-linear] relationship between polysemous senses" from a central value to its extensions (Cruse 2004: 108). As a result, the total meaning of a form can be represented as a map (Tyler and Evans 2001, 2003; Geeraerts 2010; Broccias 2013; Falkum and Vicente 2015; Evans 2004, 2015; on current approaches to polysemy in cognitive linguistics, see Falkum and Vicente 2015).

Among the various types of semantic maps, two are especially common: those that are statistically plotted and those that have a diachronic dimension. The difference between them may be viewed as roughly reflecting the two properties of a polysemous set presented above, i.e. the conceptual and the chronological relation among its components. One type belongs to the so-called 'statistically plotted maps' (Narrog and Van der Auwera 2011) and primarily has a synchronic

\footnotetext{
${ }^{3}$ On the issue of categorisation see Taylor (1989) and Tyler and Evans (2003: 42-45); consult also Riemer (2010: $167)$ and Evans and Green (2006: 29, 43). From a wider perspective of complexity theory, any categorisation is external to the universe and, hence to language, being rather tied to our theoretical and cognitive foundations. What is empirically certain or objective, if anything can be absolutely objective in science, is that empirically an object (e.g. a grammatical form) may appear in a potentially infinite amount of instances or contexts, which at an ultimate level invariably differ in certain parameters due to the complexity of the real world (see Auyang 1998: 344; Prigogine 2009: 213; Andrason 2016a). As every context is somehow different from any other, every empirical case where this object is observed is distinct from the remaining instances. At such an ultimate granularity, all uses of a form (all the senses offered by it) are dissimilar.
} 
dimension. ${ }^{4}$ This type will henceforth be referred to as an S-map. The S-map portrays the radiation of the map's components from the central to other peripheral elements and schematises the possible psychological reality of the polysemy for speakers. The central senses (i.e. those from which other values radiate) are prototypical, while the peripheral ones (i.e. those that spread from the centre value) are non-prototypical. Since, in most studies, prototypicality is correlated with frequency, the prototypical senses are the most common and the non-prototypical ones are infrequent and/or exceptional. Frequent senses are stabilised and, therefore, likely correspond to the users' representation of the meaning of a form. Infrequent senses on the contrary, do not enter into this representation, as they are rare and psychologically non-stabilised (Gries and Stefanowitsch 2006; Gries 2006; Gilquin 2006). ${ }^{5}$ This means that S-maps tend to portray what the conceptual relation in the speakers' mind may be and are quantitative, being usually plotted from empirical quantitative analyses (Lakoff 1987; Langacker 1988; De Haan 2004, 2010; Glyn 2010: 14-15; Fischer 2010; Gries and Divjak 2010: 338-339; compare also Langacker 1987: 59-60; and Evans 2004). For living languages with an infinite corpus, the quantitative analysis can rather be read in terms of probability (however, see Glynn 2010: 10-11), whereas in the case of extinct languages with a finite corpus, the qualitative data can be counted finitely offering precise frequency information. ${ }^{6}$

The advantage of S-maps is that they regularly offer statistical information and insight into what the speakers' association with the form may be. They tell us what speakers think about the form and how they relate the various meanings of it to each other. In other words, S-maps usually represent the psychological cohesion of the meaning. The most prototypical sense constitutes the map's nucleus, which the speakers associate with the form. A weakness of S-maps is, in principle, their exclusive synchronic dimension and thus possible disconnection

\footnotetext{
${ }^{4}$ To a certain degree, S-maps approximate the following types of maps previously distinguished by scholars: (a) maps designed by means of the space-driven or meaning-driven approach (cf. Zwarts (2010); (b) so-called 'second generation maps', as proposed by Sansò (2010); and (c) radial (mental) maps and semantic spaces (cf. Brugman and Lakoff 2006; Evans and Green 2006; Lewandowska-Tomaszczyk 2007; Geeraerts 2010). What unifies these types of maps (and what is also recognisable in S-maps) is that they aim to reflect the geography of the human mind (cf. Croft 2001: 364).

${ }^{5}$ Of course, frequency and its relation to prototypicality are complex phenomena. Consider, for instance, the problem of corpus representativity (i.e. whether any corpus can be viewed as representative), the context-specific frequency pattern (i.e. each corpus can exhibit different frequency distribution), the overall frequency of a context (e.g. some senses can be fully semanticised although they are rare because contexts in which they appear are per se uncommon), or the domain-specific frequency pattern (i.e. the distributional pattern of grams expressing a certain domain. In other words, the study of how a given semantic domain is expressed in the language or onomasiology as opposed to semasiology, which is the most common type of statistical analysis). However, even crude (global) frequency of the semasiological type usually gives a good picture of the prototypicality of a feature. For a more thorough discussion of the complex nature of frequency in cognitive semantics refer to Glyn (2010), Gries and Divjak (2010,2012) and Glyn and Fischer (2010); concerning the issue of prototypicality, also see Evans 2004 and Geeraerts 2010: 183-189).

${ }^{6}$ S-maps are comparable to cognitive maps, which aim to reproduce the complex knowledge of humans or their mental representations of the external word (Matlin 2005: 242). This principle also underlies network models of semantic memory and semantic categories (Matlin 2005: 262-266, 273). In the case of S-maps, the representation concern language as perceived by speakers. Accordingly, the structure of the map reflects conceptual structures (Croft 2001; Sansò 2010: 288-289). Various senses (or uses) of an item (a gram or a lexeme) are connected, delivering a web that graphically shows how speakers organise the meaning of that item. Thus, the connections between senses is assumed to be conceptual and synchronically recoverable by speakers. Therefore, such maps are commonly employed in second language acquisition or in vocabulary building as visual strategies to understand polysemy and expand the lexicon of a semantic field (Raiziene and Grigaite 2005). It is also used in explaining the encyclopaedic nature of meaning in which both the senses of an item and the semantic field(s) related to it, simultaneously intervene.
} 
from diachronic reality. ${ }^{7}$ Even more problematic is that S-maps give the impression of being intuitive, subjective and, to an extent, unverifiable (or unfalsifiable). ${ }^{8}$ The researcher proposes a link between the components of a polysemous set that is synchronically intuitive to speakers and informs how they (i.e. the speakers) currently relate the various senses of a gram to each other. As this conceptual relation is based on the synchronic psychological intuition, it leads, in some instances, to "folk-etymological" maps. Speakers postulate a conceptual relationship that seems intuitive to them but that, from a diachronic perspective, has never occurred. ${ }^{9}$

The other type of map has an inherent diachronic dimension, apart from the synchronic one, and represents the chronological connection between the components of a polysemous set attested synchronically. Given this diachronic aspect, these maps will be referred to as D-maps (they are also labelled 'classical maps'; Narrog and Van der Auwera 2011). ${ }^{10}$ D-maps aim to portray the synchronic meaning of a form not by relating its statistical nucleus to more external - and less frequent - radiations, but by employing organisational templates inferred from typological diachronic studies. In other words, the elements of a map are organised along a typological template, one of the so-called grammaticalisation paths, which provides a diachronically based cohesion of the synchronic array of senses conveyed by a form that is being mapped. In this way, the synchronic map makes reference to this form's history, showing or hypothesising the way in

\footnotetext{
${ }^{7}$ The disconnection from diachrony is visible in cognitive maps (Matiln 2005), and certain semantic maps proposed by De Haan (2004). However, diachrony is the only manner to explain the emergence of complex polysemous networks and the actual conceptual connection between all the senses. It should be noted that the synchronic orientation of S-maps does not invalidate them, simply because their objective is different. That is, S-maps aim to depict the speakers' representation of an object and not how this object has acquired its properties. Although these two processes are related (especially in the case of language), they are distinct phenomena (see footnote 9 below).

${ }^{8}$ The non-verifiability or non-falsifiability appears if one tries to determine the synchronically objective foundation of a map, i.e. the rationale other than the speaker's subjective intuition (for instance, the organisation of meaning at the neuronal or molecular level). Of course, it can also be rationalised by means of psychological argumentation, if this is viewed as scientifically convincing. In contrast, the postulated S-map can be verified and/or falsified from a diachronic perspective (see D-maps further below).

9 The folk-etymological nature of S-maps stems from their synchronic focus. In S-maps, the most prototypical sense (usually the most common) constitutes the nucleus. It is from there that speakers start to rationalise other less prototypical uses of the form, constructing explanations that are convincing to them and that may represent how the meaning is conceptualised. However, from a diachronic perspective, this direction of meaning extension is inaccurate. The area of the map that nowadays constitutes the prototype was regularly a conceptual extension from the sense that is currently peripheral. At the time, however, that sense was prototypical and the other (the one that is now central) was peripheral. In other words, all areas of the map that are presently prototypical (they function as the centres of S-maps) were non-prototypical (they functioned as peripheries), if we travel back in time. As a result, the directional organisation of the S-map will be different from what realistically occurred. An example of a folk-etymological map can be the perception of the polysemy of the word mariquita, which means "gay" and "ladybug" (a diminutive form) in Modern Spanish. Nowadays, Spanish speakers conceptually relate these two senses and derive the former from the latter given the (certainly inadequate) stereotype of a gay man. As gay men are viewed (or portrayed) as colourful and frivolous, their denomination is linked to the sense of a colourful insect. However, historically, this meaning extension has never happed. The two senses derive from two different etymological sources. The word mariquita referring to a gay man emerged from an item with the sense 'puppet, marionette' through a sequence of metaphorical meaning extensions. It is diachronically unrelated to the source of mariquita referring to an insect (Andrason 2015b).

${ }^{10}$ This class of maps is generally equivalent to maps plotted by means of the matrix-driven approach (Zwart 2010). To a certain extent, it corresponds to maps that Sansò (2010) refers to as 'first generation maps'. In all such maps, the traditional distinction between synchrony and diachrony is blurred, as synchrony is also dynamic. This stands in harmony with a common view in cognitive linguistics, whereby "there is no sharp distinction between synchrony and diachrony" (Langacker 2011: 79; cf. Hopper 1987: 142; see also the concept of panchrony in Heine et al. 1991: 248-259).
} 
which the polysemous set has actually arisen (Haspelmath 2003; Geeraerts 2010: 203; see also Moravcsik 2013: 249-252).

In most cases, D-maps are derived from a mere synchronic variation of senses. This means that the relation between the components of the grid is posited by matching senses offered synchronically with a typologically likely template schematised by a grammaticalisation path. The possibility of using grammaticalisation paths to map forms whose diachrony is unknown, or conducted on the basis of synchrony, stems from the fact that many grammaticalisation clines are nearly universal (Heine 1997; Traugott 2001). They are derived from extensive typological studies and constitute highly common and, therefore, most probable codifications of meaning extensions characteristic of grams of a certain type. Accordingly, even though the actual diachronic modifications of a form are not - or cannot be - analysed, the soundness and accuracy of grammaticalisation paths enables one to hypothesise a map (Heine et al. 1991; Heine 1997; Haspelmath 2003; Narrog and van der Auwera 2011). Moreover, with a great degree of probability, this hypothesised map reflects the actual grammaticalisation cline of the form in question. In other words, the plotted map is not only typologically plausible, but also arguably realistic - it shows how the senses of the form was actually acquired. This can be verified if direct diachronic evidence is available. To be exact, texts offered at older times should show how the polysemous map developed by gradually incorporating senses postulated by the map. Additionally, the map can be corroborated by comparative evidence and by formal properties of a gram represented by a map. ${ }^{11}$

Being derived either from synchronic or both synchronic and diachronic evidence, D-maps define the meaning of a form as a portion of a grammaticalisation cline or a cluster of such paths. Such definitions usually adopt the shape of uni-dimensional lines (or "flat" networks composed of lines), where each sense available synchronically corresponds to a historical stage on the path. Given that paths are directional, depicting the values (senses or stages) as emerging from one another in a consecutive order, or a multi-link chain from the input sense (the origin of the cline) to the final semantic attractor (the end of the cline), the line encapsulating the meaning of a form can be viewed as a vector. In this manner, the vector informs one about the direction of diachronic meaning (conceptual) extensions, also giving insight into more original states of the polysemy's evolution and its possible future states (on this type of map, see Heine et al. 1991: 221-222, 225-228, 260-261; Bybee et al. 1994: 15-19; Heine 1997: 10; Haspelmath 2003; Dahl 2000; Tyler and Evans 2003: 344-346; Sadler 2007: 33; Ariel 2008; Bybee 2010: 198-199; De Haan 2010; Van der Auwera and Gast 2011: 186-188; Deo 2015).

\footnotetext{
11 The use of a gram's structural properties as a validation of the map stems from the relationship between form and meaning. Cognitive linguists generally agree that form and meaning are related. Grammar is understood as a literal or metaphorical conceptualisation of a person's experience and, thus, the form of a given grammatical entity is connected to its meaning and function. Lexicon and core grammar constitute an inseparable continuum where central grammatical elements originate in semantically transparent and possibly iconic lexemes and/or their compositions. Input constructions are semantically and functionally consistent with the entire evolutionary growth of a given form. On the one hand, the form of the original periphrasis motivates all the senses conveyed by this construction during its entire grammatical life. On the other hand, all the senses are derivable from - or, at least, compatible with - the original inputform. Similar to semantic properties, structural properties are vestiges of the diachronic history of a gram. Therefore, structural properties may be employed to reconstruct the origin of that form and/or to corroborate or falsify the proposed mapping. For details on the relation between form and meaning, consult Heiman (1985a: 1-7, 1985b: 8, 18, 2011), Kirsner (1985: 250, 253), Givón (1985: 213-215, 2000), Bybee et al. (1994: 9-12), Croft and Cruse (2004: 1-3, 255-256), Heine and Kuteva (2007: 58, 348), Langacker (2007: 421-422) and Van Langendock (2007: 396, 401-402).
} 
D-maps are mainly qualitative and diachronically based. They are qualitative as they usually build on the array of senses irrespective of their prototypicality or frequency. The model is essentially concerned with explaining the variety of values expressed by a form, portraying it as a cognitively coherent ensemble. As this cognitive coherence between the senses is equated with the way in which the polysemy has arisen, the map has an inherent diachronic dimension. This means that the nucleus of a D-map corresponds to the most original value offered by the form, which graphically corresponds to the most initial sections of the grammaticalisation cline. D-maps indicate that synchronically the conceptual coherence and relation can mostly be recoverable for adjacent senses of a polysemous set. For the entire polysemous set, especially for extensive polysemy, the conceptual coherence between its various elements can only be achieved by reiterating the relation linking two neighbouring senses and thus by travelling, gradually, along the path. Although two adjacent senses are conceptually similar - which makes each extension and the movement along the past possible - the conceptual relation between the extreme poles of the cline is only recoverable in the path itself, which represents the $n$ reiteration of contiguous coherences. Such extreme poles may not share any semantic string and, from a synchronic perspective, they may even be semantically disconnected (Andrason and Locatell 2016; see also Givón 2000; Haspelmath 2003, 2004; Narrog and Van der Auwera 2011: 323-326).

The main advantages of D-maps are their empirical foundation and diachronic dimension. The structure of D-maps (i.e. "their geography") is based on typological diachronic universals. This structure can be regarded as more secure than geographies plotted psychologically as in various S-maps. Such universal paths were derived from empirical studies and are relatively objective and verifiable (falsifiable). Moreover, as the map also reflects an evolution specific of a gram under analysis, it can be tested with direct diachronic data or comparative evidence. This increases their objectivity and verifiability. Moreover, the D-map not only reflects human cognitive mechanisms underlying meaning extensions, but also gives access into the realistic diachrony of the form. That is, it shows how such meaning extensions have actually occurred. Given this, the D-map preserves the dynamic character of language, portraying it as a metastable phenomenon - synchronic but inherently kinetic.

However, D-maps are not flawless. Their major limitations stem from the two principal characteristics described above. First, being qualitative, they treat all the components of a given semantic network as if they were equal. Of course, scholars are aware of the fact that different components of a map have differing weights within the map and contribute to it in a distinct manner. However, even though acknowledged and sometimes even quantified, the information concerning the prototypicality or frequency is not included in this model. ${ }^{12}$ Second, by ignoring the prototypicality issue and focusing on a diachronically based cognitive cohesion, D-maps are less likely to recover what the actual cognitive association of the form is and what its psychological reality may be. They give little insight into speaker perception. In fact, even the qualitative structure of D-maps (i.e. the composition of the network) is not required to constitute a mental representation of "the relationships between meanings in speakers" minds" (Haspelmath 2003: 233). D-maps do not portray what the speakers may have in their minds, as speakers are not (at least consciously) aware of grammaticalisation paths that regulate the expansion of polysemous sets. This is especially evident for large polysemy, whose map may span an entire grammaticalisation trajectory. ${ }^{13}$ Consequently, although D-maps have conceptual reality from a diachronic perspective (they show how meanings were extended/derived by

\footnotetext{
${ }^{12}$ Quantitative data, if available, is located outside the map, typically in tables or as a part of the narrative.

${ }^{13}$ For a more detailed discussion of shortcomings of the two map types see Zwarts (2010).
} 
speakers by means of universal cognitive mechanisms), they do not imply any synchronic conceptual reality (they do not yield insight into how speakers conceptualised the meaning of a gram).

It is evident from the previous discussion that S- and D-maps constitute two distinct methodological and heuristic approaches to the mapping of meaning. As a result, the two maps do not have to coincide. First, they may differ as far as their nucleuses are concerned. That is, the centre of the S-map is inferred statistically, while that of D-maps reflects a component that is historically most original. Second, they can also be dissimilar with respect to their entire topologies, as the radiation of the S-map is mainly psychological, whereas that of the D-map is diachronic. ${ }^{14}$ The theoretical differences and explanatory mismatch of S- and D-maps have led to the opinion that the two mapping techniques are incompatible (cf. Narrog and Van der Auwera 2011). Their connections and possible harmony have, thus, not been explored. Most importantly, the two maps have not been combined into a single representation that would give access to both quantitative data and speakers' psychological perception (as the S-map does) and to the diachronic dimension with its chronological, conceptual and qualitative cohesion (as the D-map does; Narrog and Van der Auwera 2011: 327). ${ }^{15}$

In addition, apart from having their particular limitations described in the previous paragraphs, the two maps are jointly characterised by another equally important weakness. A form that is represented by means of semantic maps is typically studied in isolation from the language in which it exists and in which it has been developing. To be exact, the meaning of a construction and its model - either plotted in terms of an S- or D-map - are derived from the form's intrinsic properties and behaviour: the array of senses expressed on concrete occasions and the frequency of these senses. The item that is being modelled is represented as independent from the language system as such, and disconnected from the remaining components of this system, particularly other forms portrayed as maps. It seems as if the mapped construction existed autonomously in a type of grammatical void. The information concerning the environment in which the form is embedded is entirely missing.

This lack of the information concerning environmental factors is particularly suspicious in the case of D-maps. To be exact, D-maps suggest that all the traits of a form, observed synchronically, have arisen internally, i.e. due to a free and unconstrained development along the path, which the gram follows and with which its synchronic representation is matched. Such an approximation constitutes an important simplification of a real state of affairs. Scholars especially cognitive and grammaticalisation linguists - are well aware of the fact that the evolution of a particular gram and, therefore, the expansion of its semantic potentials and the structure of a semantic map are deeply conditioned by that gram's interaction with the system in which it has been developing (Hopper and Traugott 2003). Thus, the growth of a form and its map are not only determined by the properties included in the input formation from which the gram has emerged and which predicts, to a degree, its (i.e. that gram's) possible grammaticalisation path. Paths are always situated or embedded in a context. They are conditioned not only by their own dynamics but also by the dynamics of the environment that frames them (Bybee et al. 1994; Hopper and Traugott 2003). As a result, the mapping technique

\footnotetext{
${ }^{14}$ For a further comparison of S- and D-maps and for a description of other types of mapping models, and of their relation, see Zwarts (2010) and Narrog and Van der Auwera (2011).

${ }^{15}$ However, consult the proposals of the integration elaborated by Van der Auwera (2008) and Narrog (2010).
} 
should make reference to the relational property of meanings and show how a map, on its whole, relates to other maps and the entire system as such.

In this paper, I will propose a method of relating the two maps by enhancing the D-maps with features which, on the one hand, they lack, but which, on the other hand, are usually included in the S-maps. These features correspond to the inclusion of qualitative data (statistics/frequency) and the reference to psychological reality of the speakers. Moreover, I will show how the new proposal enables one to include another property, usually missing in semantic maps, i.e. the relation of the map to its grammatical environment and, in particular, to other maps.

\section{Proposal of improvement}

The proposal of a unification of the S- and D- maps and/or elimination of the three main weak points of D-maps explained in the previous section will be exemplified by grams that are mapped by means of the anterior path. The anterior path is one of the best known grammaticalisation clines in the verbal systems of the world's languages and probably the most regular one. It governs the life of formations that are born as resultative proper constructions ${ }^{16}$ and that, if originally located in a present time frame, gradually acquire senses of a present perfect, ${ }^{17}$ perfective past ${ }^{18}$ and nonperfective past ${ }^{19}$ (Bybee et al. 1994; Dahl 2000; Andrason 2012a, 2014). Apart from developing in a present time frame, grams of the anterior cline can also be located in past and future time frames, developing senses of pluperfects (and later, remote pasts) and future perfects (and later, simple futures). All such perfectal values can be grouped together under a meta-label of taxis (cf. Maslov 1988) and the cline represented as follows: resultative proper $>$ taxis $>$ perfective past $>$ nonperfective past. The anterior path can be rendered more fine-grained so that a great number of consecutive stages can be distinguished. For instance, the present perfect phase itself can be deconstructed into at least four senses such as an inclusive, resultative, experiential and indefinite perfect (Andrason 2012a). For the sake of simplicity, the granularity used in this paper is one of the most coarse-grained. ${ }^{20}$

\footnotetext{
${ }^{16}$ A resultative proper (e.g. it is written or he is gone) is a formation whose meaning consists of two equally relevant components: one indicates the current state and the other makes reference to an action, formerly accomplished, from which this ongoing state has resulted. Resultative proper grams are usually intransitive formations that have a ditransitive effect on transitive verbs (Nedjalkov 1988, 2001). The cline may also originate in completive constructions (e.g. acabo de decirlo "I've just said it" in Spanish).

${ }^{17}$ Perfect is a category that compresses a group of more specific values, such as inclusive perfect (an action or state holds without interruption from a determined point in the past to the present moment: I have known him since 1960), resultative perfect (a dynamic event has occurred and since then the results remain unchanged for the present state of affairs: The police have [...] caught the suspect by now), experiential perfect (the subject has an experience of having performed a given action: Fred has visited Paris several times; Kiparsky 2002: 1). These three varieties of perfects are argued to have the value of current relevance and tend to belong to the temporal or cognitive sphere of the present (Comrie 1976: 52-54; Bybee et al. 1994: 61-62; Kiparsky 2002; Nurse 2008: 154-155; De Haan 2011: 456-457). On the one hand, perfects distinguish themselves from the resultative proper by emphasising a dynamic event or activity. On the other hand, they differ from perfectives by exhibiting a complex internal structure (an anterior event that continues to the present or has continuing results) and sometimes expressing durative states or activities (Bybee et al. 1994: 54-55; Nurse 2008: 154; De Haan 2011: 450-452, 456-457).

${ }^{18}$ A perfective aspect is usually limited to a past time frame and depicts events as complete and bounded with no internal event structure. In its most exemplary use, it expresses punctual, single events (Dahl 1985: 78; 84-86; Bybee et al. 1994: 54, 82-87; Nurse 2008: 134-135; De Haan 2011: 450-451).

${ }^{19}$ The sense of a non-perfective past includes any type of past value that is not perfective.

${ }^{20}$ The anterior cline is itself a sub-type of a broader evolutionary pattern, referred to as a resultative path, which also includes a simultaneous cline. The simultaneous cline models the development of resultative inputs into stative presents and simple (i.e. non-stative) presents. In a number of languages, the resultative path, viewed as an
} 
In order to diversify the empirical foundation of this study and ensure that the new model is applicable to various linguistic systems, the paper involves two languages of a dissimilar profile: Koine Greek and Basse Mandinka. These languages belong to different linguistic families (Koine Greek is an Indo-European language, while Basse Mandinka is a member of the Niger-Congo realm, more specifically of the Mande family), they reflect distinct historical periods (the former language was used in the first and second century CE, whereas the latter is employed currently) and are or were spoken in dissimilar geographical zones (in Europe and West Africa, respectively). The two languages also constitute objects of a distinct epistemological method of analysis - Koine Greek is an extinct language with a finite and written corpus, while Basse Mandinka is a living language with a potentially infinite, but mainly spoken corpus. Lastly, they are characterised by dissimilar access to direct diachronic evidence. The chronological states of the Greek language, both anterior and posterior to Koine, are extensively documented and our knowledge of Archaic Greek, Classical Greek, Imperial Greek, Medieval Greek and Modern Greek is substantial. On the contrary, the evolution of Basse Mandinka can only be reconstructed by comparative analysis, as direct diachronic evidence is unavailable.

\subsection{Incorporating statistics - a wave model and S-prototypicality}

The first limitation of D-maps relates to their usually qualitative aspect and their lack in the provision of information concerning the statistically plotted prototypicality (henceforth referred to as an S-prototypicality). This can easily be overcome and the qualitative D-maps further accompanied by quantitative data that specify the relative weight of the senses of a polysemous set, if the meaning of a construction is modelled not as a one-dimensional line (vector) but as a twodimensional curve. In this representation, the curve is determined by two types of variables represented by two axes: one is horizontal and qualitative (the $x$ axis), while the other is vertical and quantitative (the $y$ axis). The horizontal axis corresponds to the grammaticalisation path and contains stages that are available along a given evolutionary scenario, which has been used to map synchronic senses of a gram. The vertical axis determines the statistical value or frequency of each one of such senses located on the horizontal axis, ranging from $0 \%$ to $100 \%$. The correlation of the values of the $x$ axis with the values of the $y$ axis yields a curve, certain regions of which are "lifted" vertically. These lifted sections (referred to as a peak) correspond to stages of major frequency or statistically inferred probability. To put this simply, the horizontal map (which is traced by the grammaticalisation path) acquires a vertical dimension (which reflects the degree of frequency and/or statistical probability). As a result, a one-dimensional vector that is delivered by the qualitative mapping and visualised as a portion of a cline is upgraded to a two-dimensional curve that provides two types of information: qualitative (diversity of senses) and quantitative (their frequency). In order to approximate this nomenclature to dynamic terms, such as that of a vector used in the qualitative maps, the curve can be viewed as a wave. The shape of this wave - with its kinetic motion and peak - stems from the structure and orientation of the $x$ axis that indicates the evolutionary force underlying the form, and from the values measured by the $y$ axis.

\subsubsection{Koine Greek}

In Koine Greek there are three types of grams that travel along the anterior path: Aorist, léluka (also referred to as a reduplicated or synthetic perfect) and a class of periphrastic perfect constructions (Maslov 1988; Perel'muter 1988; Bentein 2012; Andrason and Locatell 2016).

inclusive template composed of the two above-mentioned sub-clines, is used to map the semantic potential of a given gram (Andrason 2014; cf. also Maslov 1988; Bybee et al. 1994). 
The compliance of these constructions with the anterior path has been demonstrated not only on the synchronic ground, but also by means of direct diachronic evidence. For the purpose of this study, only the Aorist and léluka grams will be discussed. ${ }^{21}$

In this historical variety of the Greek language, Aorist is mainly found in three functions: a present perfect, a perfective past and a non-perfective past (Fanning 1990; Wallace 2008; Andrason and Locatell 2016). These three uses match the three consecutive stages of the anterior cline. Consequently, Aorist's qualitative semantic potential can be mapped by means of the anterior cline and the construction defined as an anterior-path gram. As far as the quantitative evidence is concerned, in the corpus analysed for this purpose, ${ }^{22}$ Aorist is typically used as a perfective past $(61 \%)$, although it is also quite commonly found in the function of a present perfect $(27 \%)$. In the remaining 6\%, Aorist is employed as a non-perfective past. $^{23}$ This quantitative information enables one to nuance the quantitative map and indicate the sections that play a more prominent role in the semantics of this gram. To be exact, the Aorist wave exhibits two peaks: a primary peak in the stage of a perfective past and a secondary, less lifted, peak in the stage of a present perfect. The relevance of the non-perfective past value is minimal.

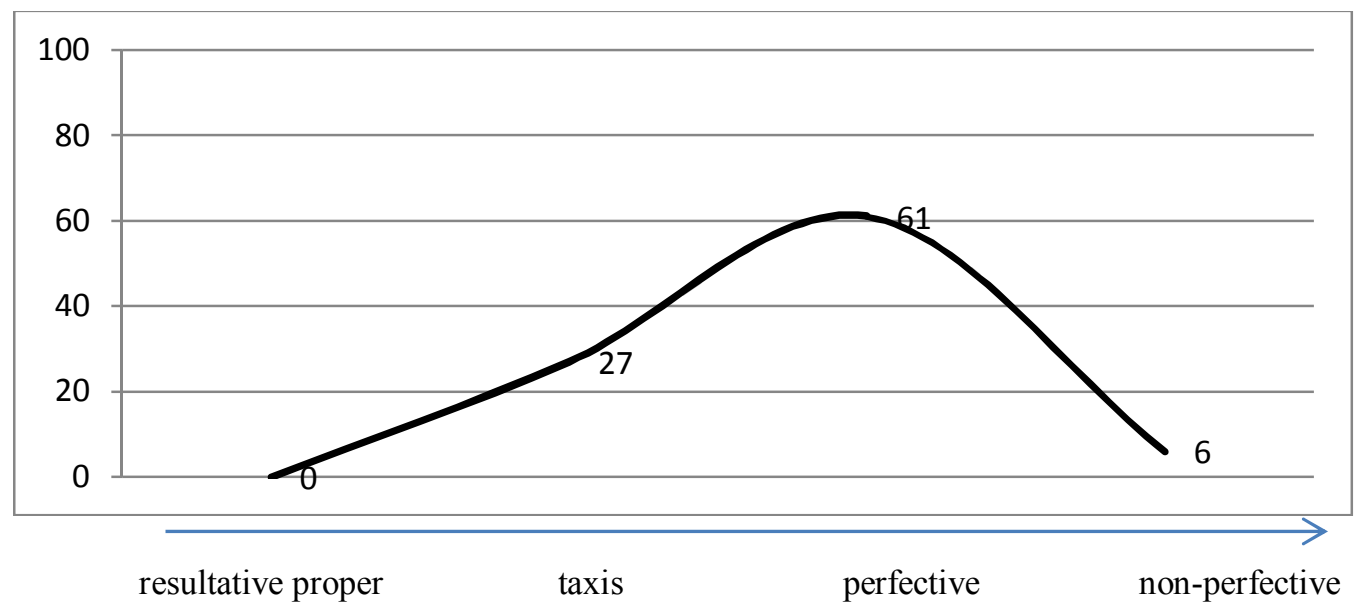

Figure 1: Wave of Aorist $t^{24}$

\footnotetext{
${ }^{21}$ The choice of these two forms is dictated by three main reasons. First, the major debate in Koine Greek concerns the status of léluka and its relationship to Aorist (for details see Andrason and Locatell 2016). Second, in the analysed corpus, léluka and Aorist are by far more common than any of the periphrastic constructions, which remain at an early stage of grammaticalisation. Third, in the studied texts, léluka and Aorist are never found with the sense of a resultative proper. Thus, this value is irrelevant for the meaning of these two constructions and their mutual relationship.

${ }^{22}$ The corpus used in this study involves the Johannian literature, namely, the Gospel of John, 1, 2 and 3 John (epistles) and the book of Revelation.

${ }^{23} \mathrm{Few}$ instances of a stative and/or non-stative present sense can be modelled by means of the simultaneous path. For the sake of simplicity, any sense offered by analysed grams that are located outside the anterior cline will be ignored in this paper. This means that the values that are related to the anterior cline but are themselves not located on it (e.g. stative, present and various modal values) will be omitted in the discussion. It is important to note that all such values have been or can be linked to the anterior cline (see Andrason 2013; Andrason and Locatell 2016).

${ }^{24}$ The uninterrupted cline of the wave makes reference to the fact that even though the stages representing the sense are depicted as discrete (each one with its own qualitative definition and statistical weight), they form a continuum containing an infinite number of meaning extensions, which smoothly and gradually transform in one another. In this way, the stages distinguished on the grammaticalisation cline (and the wave) can be viewed as prototypes in the orbit of which all the microscopic values are organised, as they either approach the postulated prototype or move away from it. The information concerning frequency provided in the figures reflects the share
} 
The other construction travelling along the anterior cline is léluka. ${ }^{25}$ This gram exhibits a sematic potential that is qualitatively similar to Aorist. That is, léluka is principally compatible with the semantic domains of a perfect and a perfective past (Fanning 1980, Maslov 1988; Perel'muter 1988; Wallace 2008; Andrason and Locatell 2016) ${ }^{26}$ In contrast to Aorist, léluka is not used as a non-perfective past. Although from a qualitative perspective, léluka semantically approximates Aorist by covering similar sections of the anterior cline, it exhibits a diametrically different profile of the wave. This stems from important differences in the quantitative evidence. To be exact, léluka is most frequently used as a present perfect $(89 \%)$, while the perfective past use constitutes only $11 \%$ of all occurrences (Andrason and Locatell 2016). This delivers the wave with only one peak of prototypicality, clearly lifted above the other parts of the curve. Moreover, the wave's peak is located in the stage of a perfect contrary to Aorist whose primary peak corresponds to the perfective past:

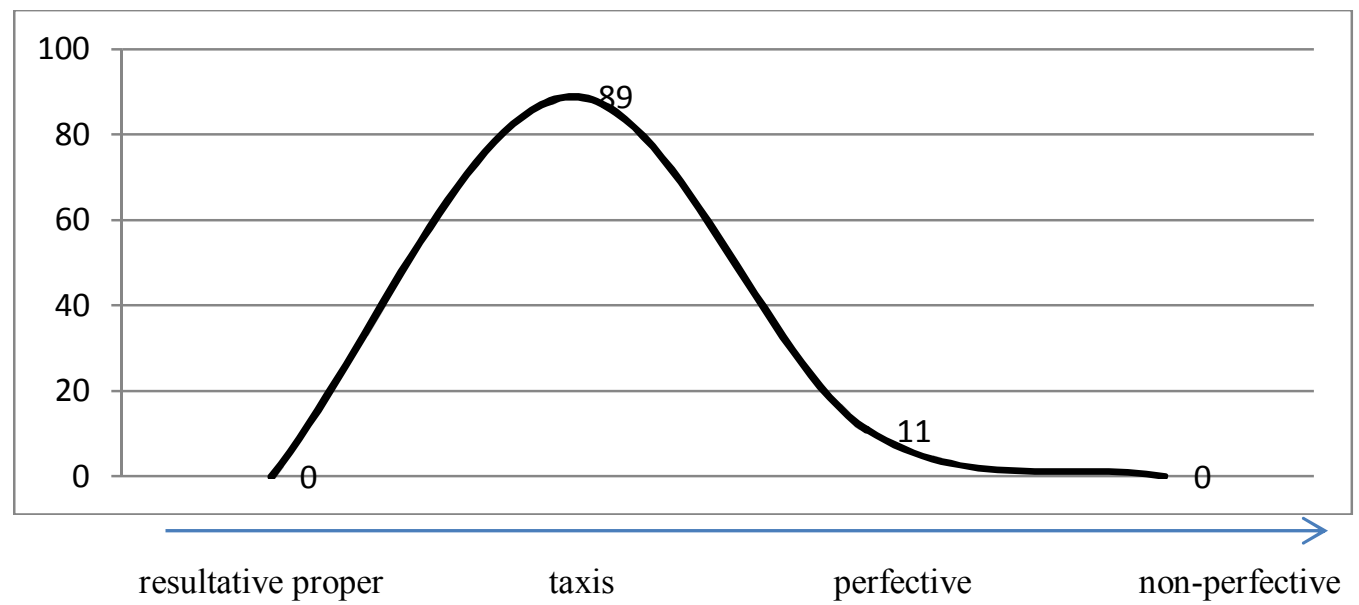

Figure 2: Wave of léluka

Accordingly, even though the qualitative maps of Aorist and léluka overlap given the similar range of their semantic potential - which is one of the main causes of their merger at posterior diachronic periods (Andrason and Locatell 2016) - the wave model enables us to preserve and represent the distinctiveness of the two forms in an elegant and easily accessible manner. The waves traced by the two grams are clearly distinct and this topological dissimilarity informs us of the different prototypicalities of these constructions - the wave of Aorist primarily matches the stage of a perfective and, secondarily, that of a perfect, while the wave of leluka matches the stage of a perfect almost exclusively.

of a given sense in the total of all the senses belonging to the anterior cline. This means that senses that are not mapped by means of the anterior cline are not included in this representation and do not contribute to the total $100 \%$ of a given gram. The labels 'perfective' and 'non-perfective' make reference to a past time frame.

${ }^{25}$ The corpus of léluka is larger than that of Aorist and included the entire New Testament (Andrason and Locatell 2016).

${ }^{26}$ Léluka also offers senses of a resultative stative, stative present and non-stative (simple) present, which have all been mapped by means of the simultaneous cline (Andrason and Locatell 2016). 


\subsubsection{Basse Mandinka}

Basse Mandinka includes three constructions whose semantic potential has been mapped by means of the anterior path. These formations are riy, naata and talye grams (Andrason 2016a). ${ }^{27}$

As far as the riy gram ${ }^{28}$ is concerned, the gram offers the following senses: a resultative proper and a perfect, mostly limited to the inclusive subtype (Andrason 2013, 2016a; see also Creissels and Sambou 2013). ${ }^{29}$ This range of the semantic potential and certain structural properties of the riy construction, as well as direct diachronic and comparative evidence, jointly suggest that the gram's meaning can be mapped by means of the anterior path (for a detailed discussion, see Andrason 2013, 2016a). If the quantitative information is incorporated,$^{30}$ the resultative proper constitutes an evident zone of statistical prototypicality, amounting to $95 \%$ of all the cases. The instances of a perfect or taxis only constitute $5 \%$. This delivers the following shape of the wave with its peak located in the first stage of the anterior path:

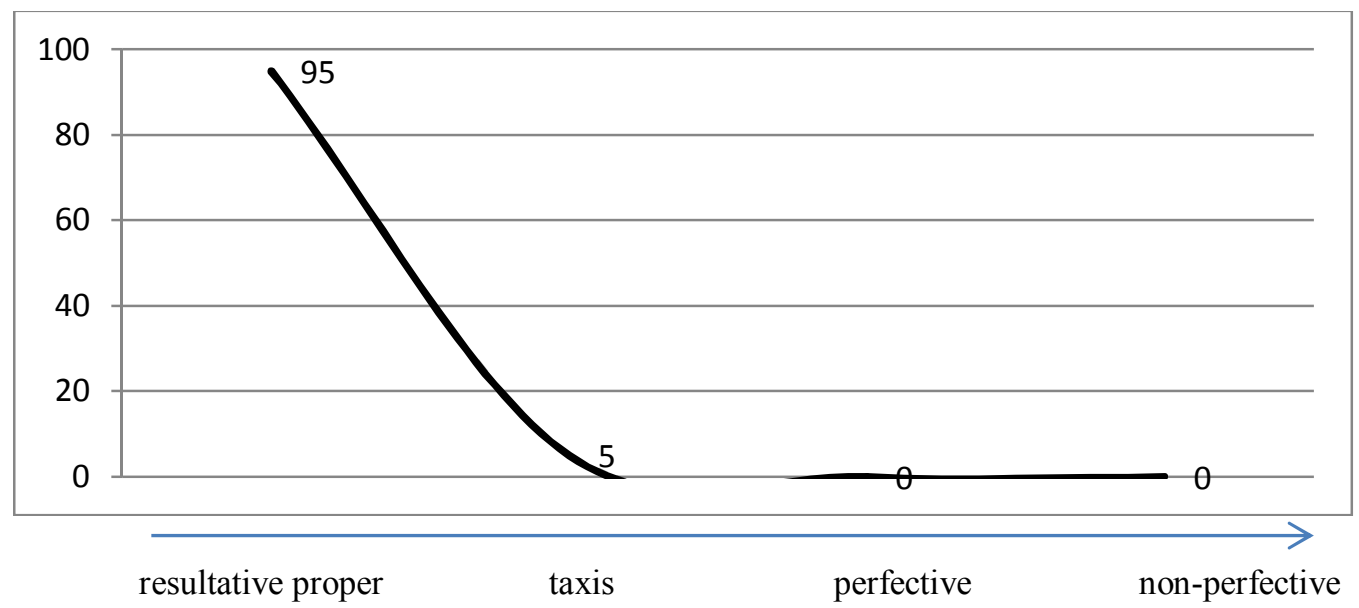

Figure 3: Wave of riy

\footnotetext{
${ }^{27}$ The riy and ye/ta forms offer maps that also make use of the other sub-cline of the resultative path, i.e. the simultaneous cline. There is also another construction (the banta gram) which, although related to the anterior path, will be omitted in this study. This stems from the fact that banta mainly travels along the evidential path offering the senses of a resultative, perfect (taxis), perfective and past invariably marked by modal undertones such as the evidential, inferential and epistemic meaning (Andrason 2016a).

${ }^{28}$ The riy form is an analytical construction compounded of the non-verbal predicator be ("to be") and the suffix -riy added to a verbal base (e.g. A be safeeriy 'It is written').

${ }^{29}$ Furthermore, this gram is commonly used as a resultative stative, stative present and non-stative present. These senses have been linked to the anterior-path map by means of the simultaneous cline (Andrason 2013, 2016a).

${ }^{30}$ This statistical evidence was extracted from a database elaborated by Andrason (2011, 2012b, 2013), which includes some 250 instances of the riy form, 150 of the naata gram and more than 400 of the ta/ye construction. As Basse Mandinka is a spoken language with practically no written texts, the corpus underlying this collection of examples was exclusively oral. This, in turn, led to quite a heterogeneous character of the collected evidence. Namely, the database includes sentences that were spontaneously constructed by the informants, fragments of stories told by the native speakers, and phrases produced by the Mandingoes on the request of the author in order to verify a given grammatical feature and/or translate a given expression from English or French. More corpus studies, especially those that are relatively coherent as far as their sources are concerned, are needed in order to render the statistics presented here more secure and representative.
} 
The naata form ${ }^{31}$ conveys the value of taxis (present perfect, pluperfect and future perfect, albeit the last one only in certain subordinated clauses) and the senses of a perfective past and a non-perfective past. In contrast to the riy gram, it fails to express the resultative proper sense (Andrason 2012b, 2016a; Creissels and Sambou 2013). Given this set of functions and due to the determined structural properties of this construction, it has been postulated that naata be mapped by means of the anterior cline (for details see Andrason 2012b, 2016a). ${ }^{32}$ The quantitative data show that the contribution of the three domains to the meaning of the gram is quite dissimilar. The perfect and perfective past values amount to $47 \%$ and $51 \%$, respectively, while the non-perfective past value constitutes no more than $2 \%$. This delivers a shape of the wave with a prolonged peak of prototypicality in the second and third stages of the cline. On the contrary, the importance of the non-perfective past domain is minimal:

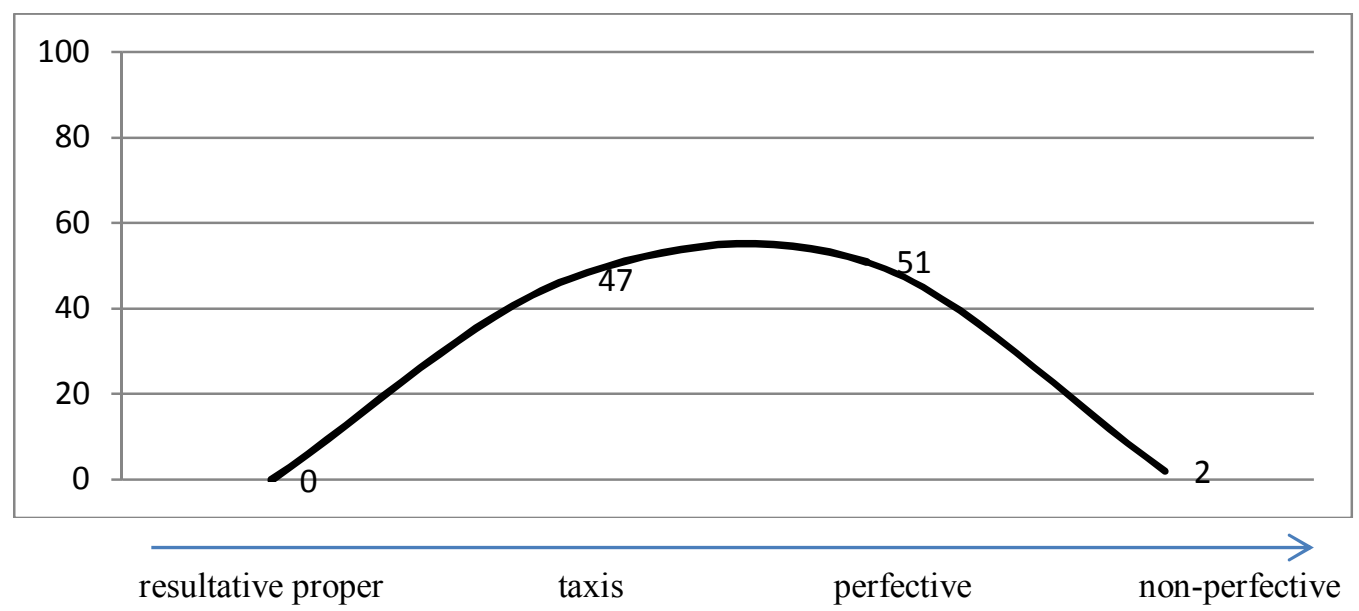

Figure 4: Wave of naata

The third formation analysed in this section is the so-called talye gram. ${ }^{33}$ This construction provides senses of a resultative proper, taxis (present, past and future perfect), ${ }^{34}$ perfective past and non-perfective past (Creissels 1983; Andrason 2011, 2016a; Creissels and Sambou 2013). ${ }^{35}$ These four senses demonstrate that the form is compatible with the entire length of the anterior path with which it has been mapped (Andrason 2011, 2016a). The quantitative information concerning the frequency indicates that the senses of taxis and perfective past are the most common, constituting $31 \%$ and $33 \%$ of all the cases, respectively. The value of a non-perfective

\footnotetext{
${ }^{31}$ This gram is derived by the entity naata (literally has come) and a verbal base (e.g. A naata taa "He has gone").

${ }^{32}$ In contrast to the riy and ta/ye (see further below in this section), the naata gram fails to convey stative and nonstative present values and, thus, makes no use of the template based on the simultaneous path.

${ }^{33}$ The $t a / y e$ form is in fact a composition of two grams: the $t a$ gram and the ye gram. The former is derived by adding the suffix $t a$ to a verbal base (e.g. $A$ naata 'He has come'), while the latter uses the predicative marker ye in the preverbial position (e.g. A ye a ke 'He did it'). The two grams appear in a complementary distribution: $t a$ construction is always intransitive while the ye construction is transitive. As their semantic potential is highly similar (de facto, in most grammars they are analysed as manifestations of the same semantic type of a gram, a perfective, a completive, a past, etc.), they are also considered jointly in this article. The cline in Figure 4 is delivered by a set-theoretical union or summation of the clines of the two grams. However, it should be noted that although the maps of the $t a$ and ye formations are similar, they are not entirely identical (for details, see Andrason 2016a).

${ }^{34}$ The sense of a future perfect is found only in certain subordinate clauses.

${ }^{35}$ The $t a$ form also offers the values of a resultative stative, a stative present and a non-stative present. These senses have been mapped by means of the simultaneous cline (Andrason 2016a).
} 
past is also relatively well-represented, amounting to $21 \%$, while the sense of a resultative proper equals $15 \%$. This delivers quite a uniform shape of a wave with only slightly pronounced peaks of prototypicality. In fact, it seems that the prototypicality peak is almost equally spread throughout the whole cline so that all the values appear as statistically prototypical (see Figure 5; for a thorough analysis, consult Andrason 2011 and 2016a):

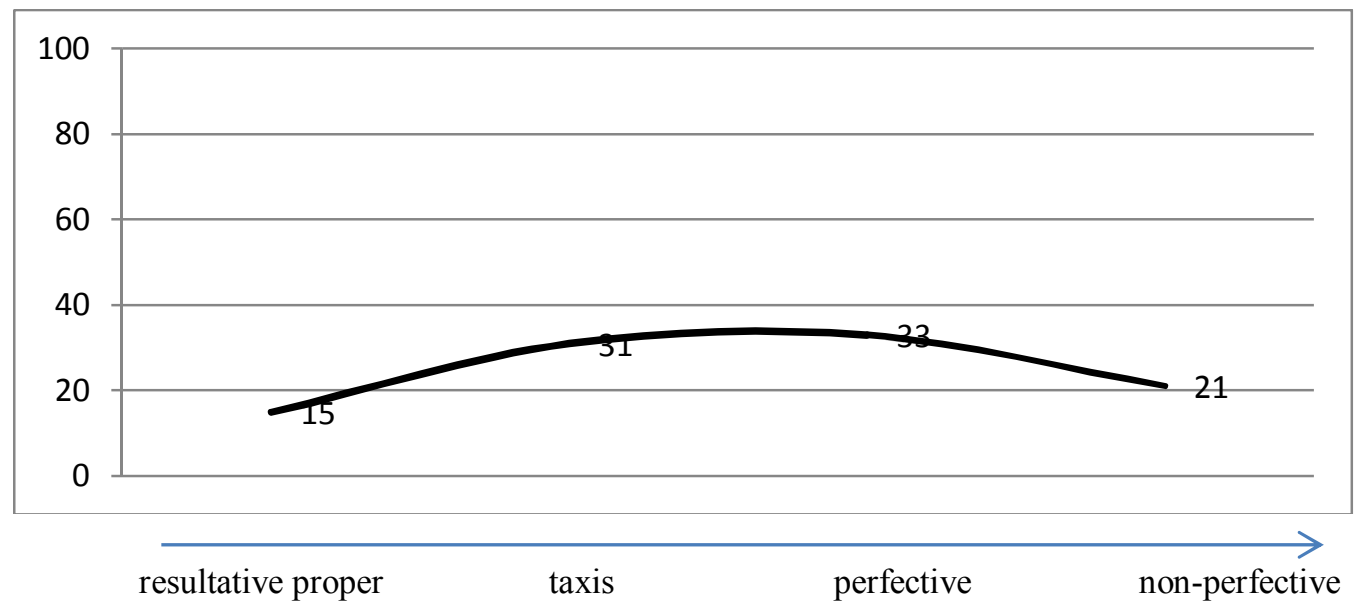

Figure 7: Wave of talye

The wave representations of the Basse Mandinka constructions enable us to capture the following important fact, which is unperceivable in D-maps. Even though the three grams are qualitatively similar (the ta/ye form has a semantic potential highly comparable with that of naata and also partially overlaps with that of riy), they are far from being quantitatively equivalent. For riy, the S-prototypicality is located at the first section of the wave (resultative proper), for naata it is placed at the two intermediate zones (taxis and perfective), and for talye it is almost evenly spread along the whole cline.

To conclude, the modelling of the meaning in terms of a wave is a simple and elegant way of introducing the quantitative data to the qualitative information, already included in a D-map, and to compare maps of forms that are qualitatively similar so that their differences with respect to a realistic usage (determined by frequency) could be estimated and/or recovered. By doing so, it prevents one from equating the meanings of grams that overlap qualitatively. It also informs one on the statistical prototypicality of elements of a polysemous set, or the S-prototypicality of a gram. That is, the internally plotted wave suggests that senses clustered around the peak area are likely to be prototypical of the gram (they constitute the semantic core of the gram) while senses corresponding to the non-peak areas are not prototypical (they are expected to constitute the semantic periphery of the gram). ${ }^{36}$

\footnotetext{
${ }^{36}$ Although the primary objective of the new model is to elegantly introduce statistical information to the D-maps, the wave provides much more descriptive and explanatory power than tables that contain frequency or statistical information for grams. Already at this stage, the model informs us about the dynamics underling the gram and the conceptual relation of senses from the historical perspective of language use (as vectors or D-maps do), as well as about the synchronic distribution of S-prototypicality (as S-maps do). Furthermore, while the arguments of the $x$ axis make reference to the crosslinguistically clustering nature of senses of verbal grams (as is also the case with vectors and D-maps), the uninterrupted line symbolising the wave overtly indicates the fuzziness of senses (as is the case of various S-maps; cf. Sansò 2010; cf. Footnote 24). That is, it represents the fact that each usage of a gram and each
} 
However, the advantages of the wave representation do not end here. On the contrary, this type of understanding of meaning offers further benefits, which will be explained in the subsequent section.

\subsection{Incorporating the environment - a stream model and P-prototypicality}

It has been explained that the wave emerges from coordinating two axes: the qualitative horizontal one (the $x$ axis), which is equivalent to a grammaticalisation path and the quantitative vertical one (the $y$ axis), which correlates each such sense with its frequency. The horizontal axis not only serves as an explanatory vehicle for the cohesion of senses offered by a given gram, but may also be imagined as representing a grammaticalisation channel, which is recursively activated in a language and has been travelled by several grams of this language. This channel has been referred to as 'a stream' (Andrason 2015a, 2016a, 2016b, forthcoming; and Andrason and Visser 2015).

A single stream can accommodate multiple waves that have been generated at different historical periods and emerged from entirely distinct original input expressions. It can also host constructions whose semantic potentials fail to overlap or grams whose senses are fully dissimilar. This means that although waves on a stream can intersect horizontally (completely or partially, as grams can have analogous or similar semantic potentials), they can likewise be disjunctive with no topological relation (if their semantic potential is qualitatively distinct). Nevertheless, whatever the exact horizontal topologies spreading along the $x$ axis and their numerical values codified by the $y$ axis are, the stream can accommodate all grams developing along the same typological template. By doing so, it enables one to compare a number of grams (even those with no topological contact) and to modularise the system into larger dynamic subparts (Andrason 2015a, 2016a, 2016b, forthcoming; Andrason and Visser 2015). ${ }^{37}$

Being itself a dynamic notion (just like a vector or a wave), a stream offers definitions of grams in terms of their relative advancement, i.e. as more conservative (the topologies of these waves and, especially, their frequency peaks are located in less advanced sections of the $x$ axis) or more advanced (the topologies and frequency peaks are located in more advanced sections of the $x$ axis). The advancement relates both to qualitative (the $x$ axis) and quantitative (the $y$ axis) properties. These dissimilarities in the degree of advancement reflect chronological differences and the fact that waves within the same stream have been generated at distinct historical periods. Older waves have been travelling the stream for a longer time - therefore, their entire semantic potentials (the total topologies of their waves) and peaks of prototypicality extend to more advanced sections of it. On the contrary, younger waves have travelled the stream less intensively and reached less advanced regions, both in terms of their entire range of senses and peaks of prototypicality.

By introducing the notion of a stream, a wave ceases to be an isolated phenomenon. On the contrary, it becomes situated, as it is always accompanied by other waves. The wave becomes

meaning extension are different from any other, if the granularity level of the analysis is fine-grained enough (for more discussion concerning the implications of waves see the subsequent section 2.2 and 2.3, and the conclusions).

${ }^{37}$ It should be noted that while the $x$ axis in a gram's wave is a gram-specific phenomenon, the axis $x$ of the stream refers to an abstract, more general and usually coarse-grained, grammaticalisation template that have been recursively activated in the language of study. This means that it encompasses and generalises over a number of specific grammaticalisation processes (which are to a degree dissimilar at more granular levels of the description). 
a wave in context. It may be preceded (and, thus, hindered) by an older, more advanced, wave and it can be followed (and, hence, pressed) by a younger, less advanced, wave. ${ }^{38}$ The travelness is now conditioned not only by the wave's own dynamics but also by the dynamics of the other waves on the stream. The relative position of a wave on the stream and its relation to the other waves, in turn, enables one to determine certain features of the meaning of a form that are conditioned by the environment. In this manner, the meaning ceases to be an entirely internal phenomenon, which uniquely depends on the atomic or inherent properties of the gram, viz. senses and their frequency, disconnected from the other components of the system in which this gram exists. The meaning is conditioned not only by the structure of a wave (semantic potential and the statistical distribution of its components), but is also dictated by the interaction of the gram's wave with the other grams traveling along a shared stream. At this moment, both the peaks of prototypicality of a map and its uniqueness on the stream are relevant for a more comprehensive understanding of prototypicality. Arguably, a gram is grammaticalised as the expression of a given semantic domain (available on the path) if this domain is statistically prototypical in its internal semantic potential (it constitutes the wave's peak) and if the gram's peak surpasses the waves of the other grams at the stage of the stream representing this semantic domain (inversely, if the internal statistical prototypicalities of the other maps are lower). Consequently, the model of verbal semantics in terms of a wave situated on a stream demonstrates that important properties of a gram stem not only from its inner properties, but also from the relationships it establishes with other components of the system. In a way, relations that are usually viewed as exogenous become interiorised as the gram's endogenous characteristics. Consequently, the gram's prototypicality can be viewed as a product of its own S-prototypicality and the S-prototypicalities of the other waves of the stream. This type of prototypicality will be referred to as a product prototypicality or P-prototypicality.

\subsubsection{Koine Greek}

Since Aorist and léluka are mapped by means of the anterior path and their waves are organised along analogous $x$ axes, they can both be placed on the same stream recursively employed in the Greek language, i.e. the anterior stream. This can be postulated even though the two grams derive from two different original locutions and were shaped at two different distinct periods. Chronologically, Aorist is an older gram, while léluka is a younger formation. By locating Aorist and léluka on the shared stream, the relational properties of the two grams can be estimated and their systematic status postulated.

The topologies of the two formations indicate that the Aorist wave is more advanced (its primary peak is located at the perfective past stage), while the léluka wave is more conservative

\footnotetext{
${ }^{38}$ That is, the older wave has travelled further up the stream and moved more to the right of the diagram. Therefore, it metaphorically hinders the progress of the following, younger wave. If this older wave did not exist, the younger wave could rapidly spread to further extensions or stages on the path. Indeed, this occurs in pidgins. As older waves are "catastrophically" removed, younger waves are rapidly extended to semantic spaces newly liberated (cf. Andrason 2008, Andrason and Visser 2015). In contrast, the younger wave has travelled the stream to a lesser extent and covers the areas more to the left in the figure. Therefore, it exerts a type of pressure on the more advanced wave, constantly invading the semantic space typically associated with that latter construction. At first, the instances of this are perceived as irregularities or errors contravening the linguistic norm. With time, as this pressure persists and intensifies, the younger wave totally inundates the semantic area, which previously constituted the exclusive domain of the older wave. As a result, it forces the older gram to move further to the right. To conclude, the two waves coexist in a type of entanglement. The dynamics of the older wave influence the dynamics of the younger wave, and vice-versa.
} 
(its peak is at the taxis stage). Further relational traits emerge from analysing the oscillation that exists between the peak of one gram and the wave of the other. To be exact, léluka overcomes Aorist in the taxis stage by 62 points (compare $89 \%$ of léluka versus $27 \%$ of Aorist), while Aorist surpasses léluka in the perfective past stage by 50 points (compare $11 \%$ of léluka versus $61 \%$ of Aorist).

The situatedness of léluka in the environment conditioned by Aorist has important bearings on its semantics. Namely, the absolute predomination of the Aorist wave in the perfective past section of the stream suggests that even though the value of a perfective past is represented in the semantic potential of léluka (as it constitutes a respectable $11 \%$ of all the cases), it is much less prototypical (almost negligible) from the perspective of the P-prototypicality of the system. Simply put, the properties of Aorist, which is the perfective past form par excellence $(61 \%)$, hide the léluka's compatibility with the perfective past domain as, in this area, the léluka wave is covered by the Aorist's wave.

The interaction of the waves and their mutual impact are more explicit if the situatedness of Aorist is analysed. Even though Aorist expresses the taxis nuances nearly in a third of its total occurrences (27\%), which can be viewed as highly relevant for the internally plotted map of this gram, the impressive predomination of léluka in this stage (89\%) and, especially the fact that it overcomes the Aorist's wave in this function by 62 points, hide this type of semantic compatibility of Aorist. This, in turn, further emphasises the systemic synchronisation of Aorist with the perfective past domain (cf. Figure 5).

As a result, the P-prototypicality of léluka corresponds to taxis, whereas that of Aorist to a perfective past. This implies that the systemic meaning of léluka does not only derive from its own internal properties (the structure of the wave as plotted on the ground of the gram's own occurrences), but is also conditioned by the behaviour of Aorist and, in general, the structure of the stream on which léluka travels. In reverse, the meaning of Aorist depends both on its inherent characteristics and on the organisation of the stream on which it coexists with léluka. In both cases, the environment - in particular, the other gram of the stream - significantly influences the form's meaning by determining its systemic or product prototypicality.

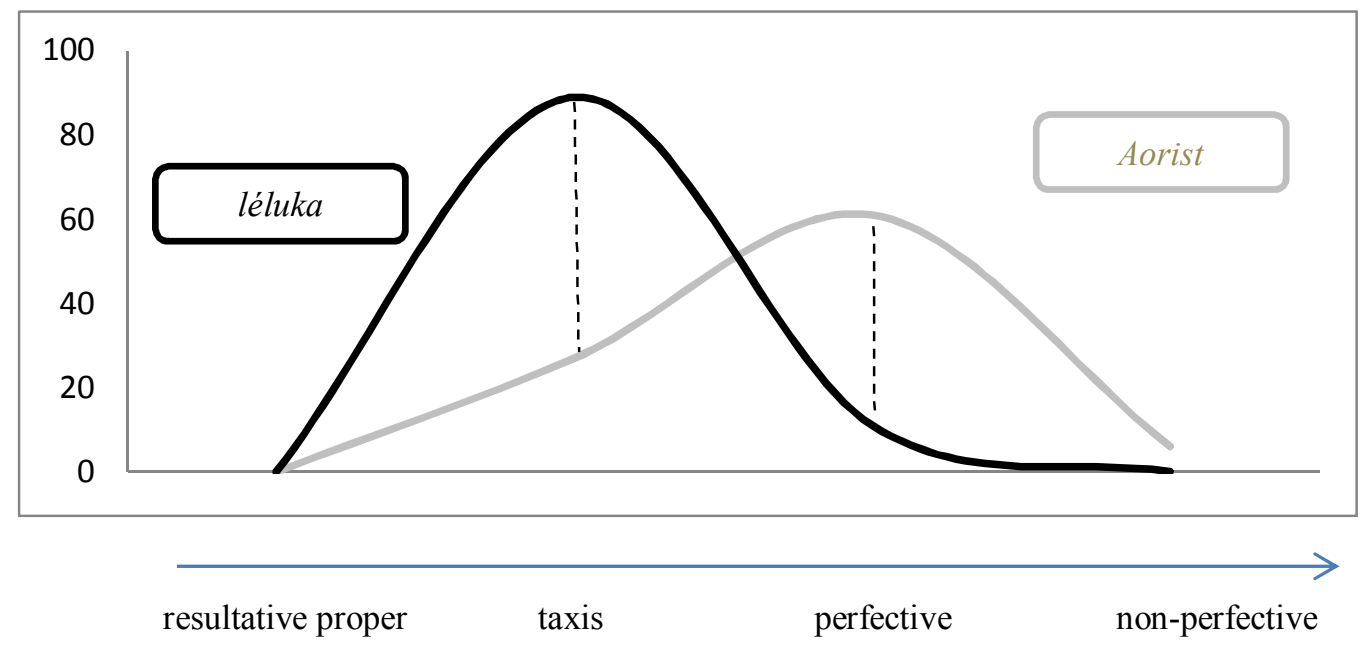

Figure 5: Anterior stream in Koine Greek 


\subsubsection{Basse Mandinka}

The interaction of the waves of the anterior stream in Basse Mandinka provides another example of how important the structure of the stream can be for the semantics of a gram and how the S-prototypicality of a form does not exhaust the total information concerning its meaning. In section 2.1.2, I explained that the three constructions - riy, naata and talye-could be mapped by means of the anterior path. This means that they can all be placed on the same stream which, in turn, constitutes one of the modules of the verbal system of this language (Andrason 2016a). One should note that, thanks to the stream model, the riy and naata formations can be dynamically compared, even though their semantic potentials are, in principle, topologically disjunctive. If the evidence provided in the previous section is adapted to the stream representation, the following can be observed: riy locates its front at the first stage of the stream (a resultative proper), naata places it at the second and third stages (taxis and perfective past) and talye displays a relatively uniform wave and distribution of its S-prototypicality (it is mainly raised in the intermediate areas of the stream [perfect and perfective past] and, albeit slightly less so, in the final fragment [non-perfective past]). Consequently, the ta/ye gram seems to be the most advanced - its aggregate topology reaches the furthest sections of the $x$ axis and its peak, albeit broad, is advanced matching even the last stage of the stream. The naata form is less advanced, at least as far as its peak is concerned - it is mainly located in the intermediate section. The rig construction is the most conservative both in relation to its overall topology and peak - it is restricted to the initial section of the stream.

The structure of the anterior stream in Basse Mandinka and especially the interaction of the S-prototypicalities of the three formations have some important bearings on their (i.e. these grams') semantics. This is particularly evident in the case of the talye construction. As explained in section 2.1.2, the wave of this form is fairly even. That is, it exhibits a relatively uniform S-prototypicality peak spanning almost the entire anterior cline. Since the wave is quite evenly distributed along the entire $x$ axis, the other waves of the anterior stream seem to contribute importantly to the systemic semantics of the ta/ye gram or its P-prototypicality. To be exact, given that riy clearly predominates in the resultative proper domain (it surpasses the ta/ye gram by 80 points), while naata does so in the sections of taxis and perfective past (it overcomes the ta/ye form by 16 and 18 points, respectively) and given that it is the ta/ye construction that predominates in the non-perfective past domain (its peak is higher than the naata gram by 19 points), the P-prototypicality of ta/ye may correspond to a non-perfective or a simple past, which is a general past that can express all types of aspectual nuances. Consequently, the meaning of the talye form is not only inferable from its own S-prototypicality, but also derives from the interaction of its wave with the waves traced by the other grams (and their S-prototypicalities). It is thus conditioned by the structure of the stream. Inversely, the interaction of the three waves suggests the following P-prototypicalities of the riy and naata constructions. The relation of the riy wave and the waves of naata and ta/ye indicates that the systemic prototypicality of this form corresponds to the resultative proper. In this part of the stream, the riy gram surpasses the remaining waves by 95 points (versus naata) and 70 points (versus $t a / y e$ ). The present perfect nuances are, on the contrary, almost negligible, being hugely overcome by the naata (47 points) and talye (31 points) waves. Lastly, the situatedness of the naata form implies that the non-perfective domain all but completely fails to contribute to the P-prototypicality of this form (it is surpassed by the talye gram by 19 points), which would in turn strengthen the relevance of the domains of taxis and perfective past, already prototypical given the internal statistics of the naata construction: 


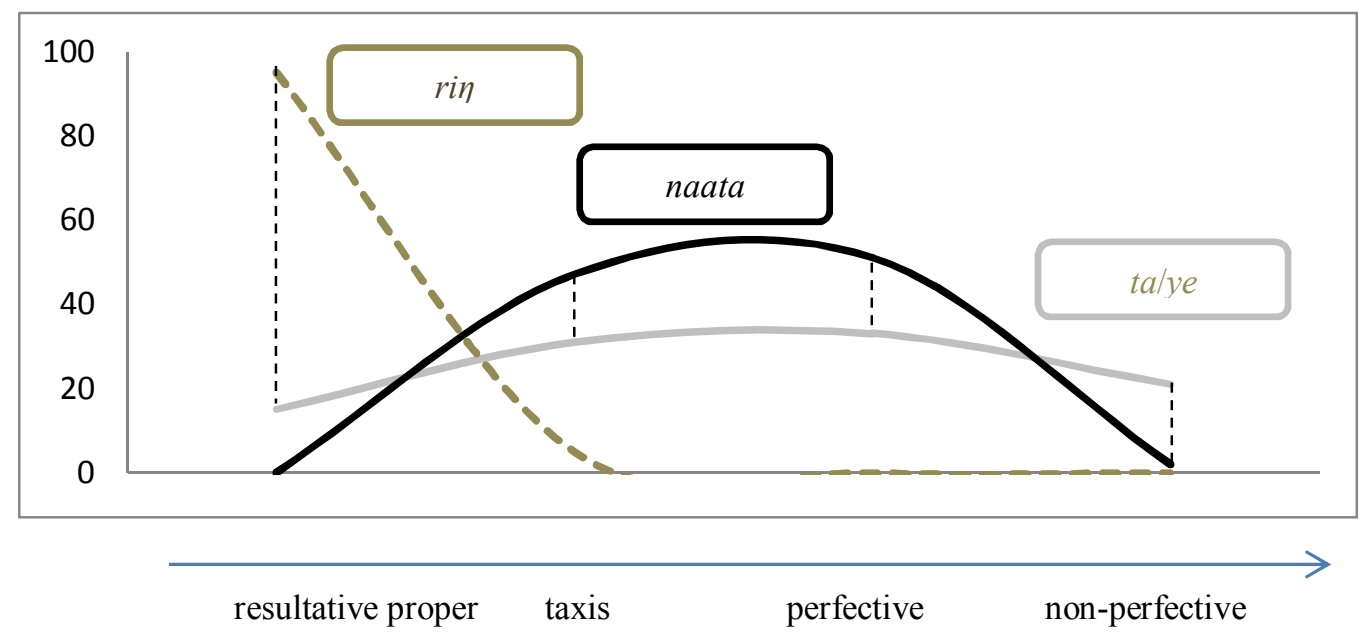

Figure 6: Anterior stream in Basse Mandinka

To conclude, the situated wave is highly explanatory. It informs us on the semantic potential that has conceptual reality from a diachronic perspective (as D-maps do). It informs us about the distribution of the internally plotted S-prototypicality (as is the case with the S-maps and nonsituated waves discussed in section 2.1). Furthermore, it relates the gram to the other grams developing along comparable evolutionary scenarios. The outcome of this interaction is the P-prototypicality that suggests how the wave should be interpreted in the contexts of the other waves of the stream. The model also yields predictions for the subsequent and previous evolutionary stages. For instance, given the structure of the stream, it is likely that in future, the wave of the ta/ye gram will increase its S-prototypicality in the stage of a non-perfective past and decrease the relevance of the domain of a perfective past and, especially, of a resultative proper. All such changes are stimulated by the pressure exerted by the two younger waves: the naata wave and the riy wave.

The situated wave model also suggests to what degree the uses of a gram in neutral contexts or in contexts where non-prototypical senses are profiled (especially in terms of P-prototypicality) is contaminated by the prototypical sense(s). I have frequently mentioned this phenomenon (for a detailed discussion see Andrason 2016a). A single use of the gram in a specific moment and place activates a particular sense out of the semantic potential of that form. However, even though one sense is profiled, the rest of the semantic potential is still present, possibly colouring this use. This colouring is the strongest in two situations. It is heavy if the context is highly unspecified. It is also evident if the wave of the gram is highly uneven (like the rig wave), so that the contribution of the non-prototypical sense to the total meaning of that form is minimal. In the former case, the most prototypical sense will be immediately activated because it is the most probable. In the latter case, the disproportion in the semantics of the gram will naturally colour the extremely rare senses by what is (perceived as) "the norm" (for details, consult Andrason 2016a and the reference therein). Both phenomena are due to the synchronic conceptual and/or psychological reality to which the situated wave model give access (see the next section). 


\subsection{Incorporating psychological reality - towards synchronic conceptual map}

The P-prototypicality can additionally give us some insight into the conceptual or psychological reality concerning the gram's meaning, showing how and why grams are identified by the speakers with certain domains. It can demonstrate what the association of the users might be (especially, if we cannot consult the speakers) or why they are as they are (for instance, in a living language whose speakers can be consulted). This relationship between P-prototypicality and psychological perception stems from the following facts: On the one hand, grammar, viewed as an autonomous system, is moulded by frequencies. On the other hand, speaker perception of grammar and its use have a statistical foundation (humans being de facto big statistical machines; Ariel, 2008; Bybee, 2010). As a result, the P-prototypicality is expected to match the speaker's intuitive association of the form with a meaning or the psychological reality of the form.

This means that the P-prototypicality - which is objective and easily accessible, as it is directly inferred from the structure of the stream - can be used to hypothesise the psychological prototypicality, which is either less straightforwardly recognisable (cf. section 1) or cannot be directly posited for systems that do not have native speakers. Thus, it constitutes a method that may especially be applied to extinct ancient languages and to research, which are exclusively based on corpus studies.

Knowing the P-prototypicality and the structure of the wave, it is also possible to hypothesise the psychological geometry of the meaning and to propose a map that would have synchronic conceptual reality. As explained previously, the conceptual reality of D-maps and thus of the waves and streams (which are built around the $x$ axis inherited from the D-maps) is principally diachronic. However, as the P-prototypicality is arguably correlated with the psychological prototypicality, it indicates the sense or a cluster of senses that are the most active synchronically, i.e. the sense(s) that produce(s) the greatest number of possible meaning extensions. This area of the wave is the most semanticised and hence most strongly attached to the form. It is thus from there that other senses will be conceptually drawn radiating from the maps' centre to the periphery. Among the peripheral senses, those that cover the area of the wave to the right of the peak (i.e. senses that are not prototypical yet) will be perceived as novelties and/or as more metaphorical as they usually arise through active meaning extensions. That is, here the direction of extension posited by the wave (and a D-map) and the direction of a psychological map coincide. In contrast, senses located to the left on the wave (i.e. senses that are no longer prototypical) will be perceived as archaic or as restricted to determined genres (e.g. to written and narrative corpus) and styles (e.g. to official language). The less lifted a given sense is on the stream the more peripheral it is for the map conceptually constructed by speakers. Thus, the radial circles of the core and peripheral areas of the map may be postulated as well as the direction of conceptual relationship that is bestowed with synchronic reality.

\subsubsection{Koine Greek}

In the case of Koine Greek, the speakers' associations and the psychological reality of the two grams can only be hypothesised, as no informant can be consulted. However, given the P-prototypicalities of Aorist and léluka and the plausible assumption that their values should be analogous to the speakers' psychologically grounded prototypicalities, one may postulate that léluka was mainly perceived as a taxis or perfect form, whereas Aorist was associated with the sense of a perfective past (Andrason and Locatell 2016). The psychological maps of 
the two grams could, in turn, be posited as radiating from these central areas to more peripheral zones: perfective past in the case of léluka and taxis and non-perfective past in the case of Aorist (see Figure 7 below). Perfective uses of léluka and non-perfective uses of Aorist may have had a strong pragmatic effect on speakers' perception given that these values are highly peripheral. In contrast, the use of Aorist in taxis contexts could have been perceived as more "solemn" than an analogous use of léluka. However, as this value is less peripheral than the other non-prototypical sense of Aorist, its pragmatic effect may have been weaker.

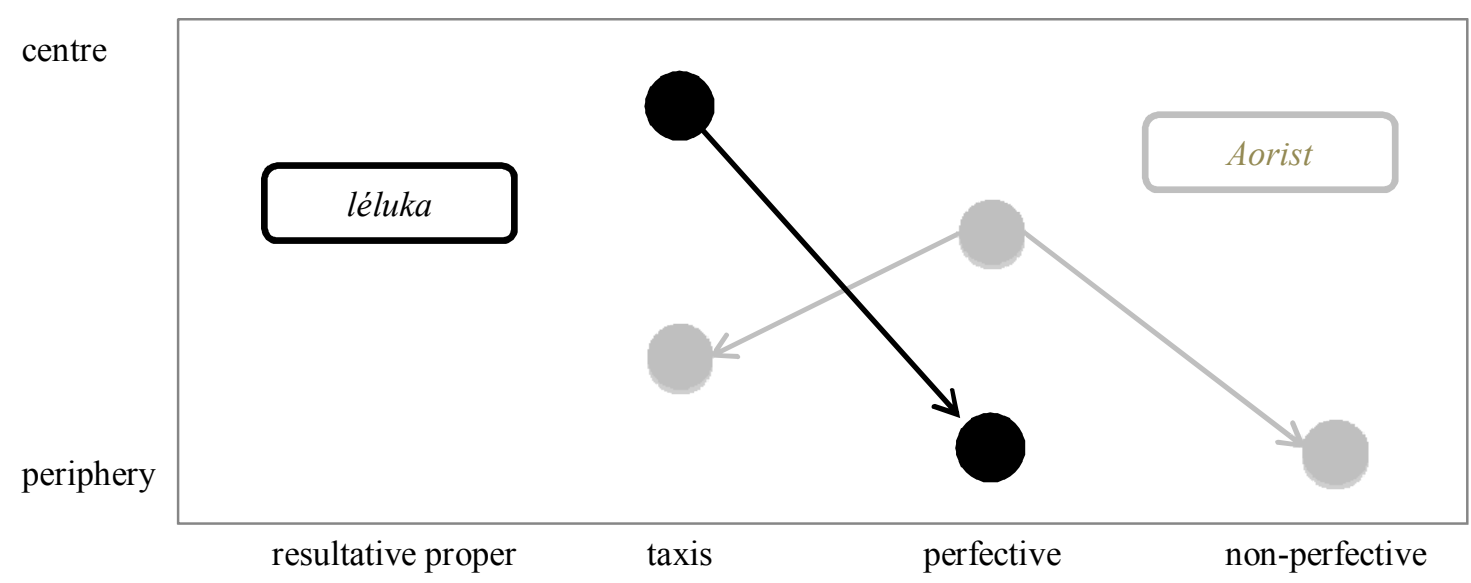

Figure 7: Psychological maps of léluka and Aorist

\subsubsection{Basse Mandinka}

As far as Basse Mandinka is concerned, the P-prototypicalities of the riy, naata and ta/ye grams correspond to a resultative proper, a perfect and a perfective past, and a general (or nonperfective) past, respectively. These three P-prototypicalities derived statistically from the corpus arguably correspond to the psychological prototypicality areas as perceived and conceptualised by speakers. Indeed, this hypothesis has been corroborated by the native speakers interviewed for this study. Out of the 20 persons, all related the rin form with a resultative proper domain. Likewise, all the informants associated the naata construction with a present perfect or perfective past. Lastly, $90 \%$ of the speakers (18 out of 20) defined the ta/ye formation as a past tense (two others rather viewed it as a perfect; Andrason 2016a). This information enables us to postulate the following psychological maps (see Figure 8). The map of the riy form radiates from its centre (resultative proper) to the periphery (taxis). The map of naata consists of two relatively equal semi-central areas, thus with no evident direction of radiation. The map of talye is composed of a semi-central area of past, which includes two senses (perfective and non-perfective past) from which the taxis sense radiates. 


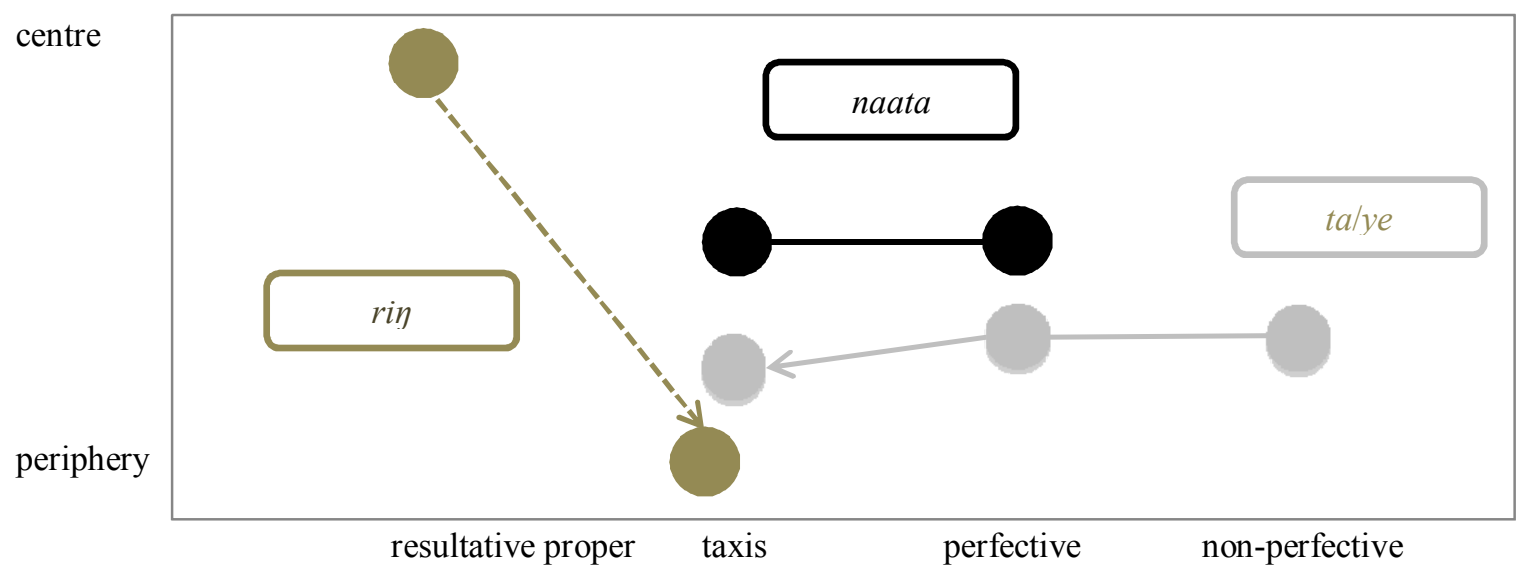

Figure 8: Psychological maps of riy, naata and talye

To conclude, the S- and P-prototypicalities and the model of situated waves enable one to recover the psychological prototypicality area and to postulate the structure of a map that would have synchronic conceptual reality. In such maps, the fuzziness of waves disappears due to the regularising mechanisms of human perception and the human tendency to categorise reality into neat and discreet categories. ${ }^{39}$ A dynamic and fuzzy model becomes static and neat. Complexity gives way to simplicity. It should also be noted that this distance from the central sense to peripheral extensions also indicates the degree of possible contamination in contexts where non-prototypical values are profiled. For example, perfective past uses of the léluka in Koine Greek and taxis uses of riy in Basse Mandinka are heavily contaminated by the prototypical sense, taxis and resultative proper respectively. Lastly, by using the matrix grid (or the matrix semantic space), which underlies waves and their stream, the psychological mapping and especially the positioning of the nodes become less arbitrary. As has been explained in section 1, the diachronic grid is empirical and objective.

\section{Conclusion}

In this article, I developed an elegant method of expanding D-maps by including statistical or frequency evidence and the information concerning their environment. The former delivered the S-prototypicality of a gram (which is a product of its own wave), while the latter yielded the P-prototypicality (which is a product of the gram's wave and the waves of the other forms travelling along the stream). It was additionally shown that P-prototypicalities and situated waves could be employed to postulate psychological prototypicalities and maps that have synchronic conceptual reality. Accordingly, one could gain insight into the speakers' perspective and their (geometrical) representation of a gram's meaning.

The waves and streams, and S- and P-prototypicalities have already been applied to a variety of languages and their usefulness have been corroborated (Andrason 2016a, 2016b, forthcoming; Andrason and Locatell 2016). In contrast, the adequacy between the P-prototypicality and the

\footnotetext{
${ }^{39}$ Our cognition and perception modify reality. They fill in blanks (i.e. add information that is not present in the external world), impose order in fragments of the world that are not regular, and improve narratives typically removing what does not "fit" (Cooper 2007, Macnick and Martinez-Conde 2010, Trivers 2011, Wade and Tavris 2012). Some of the effects of these mechanisms are discreet categorisation and over-regularity of our interpretations of reality.
} 
psychological prototype on the one hand, and the derivability of psychological maps from situated waves on the other hand, should be regarded as provisional. Certainly, more empirical research on living languages is needed to verify the two types of relationships hypothesised in the present study.

\section{References}

Andersen, H. 1973. Abductive and deductive changes. Language 49: 765-793.

Andrason, A. 2008. The BÚNA construction in Pidgin Icelandic. Íslenskt mál 30: 121-140.

Andrason, A. 2011. Semantics of the ta construction in Basse Mandinka. Linguistica Copernicana 2(6): 221-244.

Andrason, A. 2012a. When imam perfect 'becomes' a past. Balkanistika 25: 75-103.

Andrason, A. 2012b. The meaning of the NAATA + infinitive construction in Basse Mandinka. Lingua Posnaniensis 40: 7-19.

Andrason, A. 2013. Mapping the meaning of the be riy formation in Basse Mandinka. Journal of West African Languages 40(2): 101-133.

Andrason, A. 2014. From resultatives to present tenses - simultaneous path of resultative constructions. Italian Journal of Linguistics 26(1): 1-58.

Andrason, A. 2015a. Towards the ocean of the Biblical Hebrew verbal system. Folia Orientalia 52: $15-36$.

Andrason. A. 2015b. From Iceland to Congo - navigating with MAPS through the WAVES and STREAMS of Biblical Hebrew verbal semantics. Talk at the Department of Ancient Languages, Stellenbosch University, 3 March 2015.

Andrason, A. 2016a. A Complex System of Complex Predicates: Tense, Taxis, Aspect and Mood in Basse Mandinka from a Grammaticalization and Cognitive Perspective. $\mathrm{PhD}$ dissertation, Stellenbosch University.

Andrason, A. 2016b. The complexity of verbal semantics - an intricate relationship between QATAL and WAYYIQTOL. Journal of Hebrew Scriptures 16: 1-95.

Andrason, A. forthcoming. Navigating with maps through the waves and streams of Biblical Hebrew - A pilot model of a grammaticalization approach to verbal semantics with the inclusion of quantitative data and maps' interaction. In C. Miller-Naudé and J. A. Naudé (Eds.) Biblical Hebrew Verbal System. Winona Lake: Eisenbrauns.

Andrason, A. and C. Locatell. 2016. forthcoming. The perfect wave: A cognitive approach to the Greek verbal system. Biblical and Ancient Greek Linguistics 5. 
Andrason, A and M. Visser. 2015. Affordances Perspective and Grammaticalization Incorporation of Language, Environment and Users in the Model of Semantic Paths. Studies in Second Language Learning and Teaching 5(4): 663-696.

Antilla, R. 1989. Historical and Comparative Linguistics. Amsterdam: John Benjamins.

Broccias, C. 2013. Cognitive grammar. In T. Hoffmann and G. Trousdale (Eds.) The Oxford Handbook of Construction Grammar. Oxford: Oxford University Press. pp. 191-210.

Brugman, C and G. Lakoff. 2006. Cognitive topology and lexical networks. In D. Geeraerts (Ed.) Cognitive Linguistics: Basic Readings. Berlin: Mouton de Gruyter. pp. 109-138.

Bybee, J. 2010. Language, Usage and Cognition. Cambridge: Cambridge University Press.

Bybee, J., R. Perkins and W. Pagliuca. 1994. The Evolution of Grammar. Chicago: The University of Chicago Press.

Carstairs-McCarthy, A. 2010. The Evolution of Morphology. Oxford: Oxford University Press.

Comrie, B. 1976. Aspect: An Introduction to the Study of Verbal Aspect and Related Problems. Cambridge: Cambridge University Press.

Cooper, J. 2007. Cognitive Dissonance. Fifty Years of a Classic Theory. Los Angeles: Sage.

Creissels, D. 1983. Éléments de grammaire de la langue mandinka. Grenoble: ELLUG.

Creissels, D. and R. Sambou. 2013. Le mandinka: phonologie, grammaire, textes. Paris: Karthala.

Croft, W. 2001. Radical construction grammar. Oxford: Oxford University Press.

Croft, W. 2003. Typology and Universals. Cambridge: Cambridge University Press.

Croft, W. and D. Cruse. 2004. Cognitive Linguistics. Cambridge: Cambridge University Press.

Cruse, A. 2004. Meaning in Language. Oxford: Oxford University Press.

Cuykens, H. and B. Zawada. 2001a. Introduction. In H. Cuykens and B. Zawada (Eds.) Polysemy in Cognitive Linguistics. Amsterdam: John Benjamins. pp. i-xxvii.

Cuykens, H. and B. Zawada. (Eds.) 2001b. Polysemy in Cognitive Linguistics. Amsterdam: John Benjamins.

Dahl, Ö. 1985. Tense and Aspect Systems. Oxford: Blackwell.

Dahl, Ö. (Ed.) 2000. Tense and Aspect in the Languages of Europe. Berlin: Mouton de Gruyter.

De Haan, F. 2004. On representing semantic maps. E-MELD Language documentation conference 2004: Workshop on linguistic databases and best practice. University of Arizona, 
manuscript. pp. 1-12 Available online: www.emeld.org/workshop/2004/ deHaan-paper.doc (Accessed 28 April 2015)

De Haan, F. 2010. Building a Semantic Map: Top-Down versus Bottom-Up Approaches. Linguistic Discovery 8(1): 102-117.

De Haan, F. 2011. Typology of Tense, Aspect, and Modality Systems. In J. J. Song (Ed.) The Oxford Handbook of Linguistic Typology. Oxford: Oxford University Press. pp. 445-464.

Deo, A. 2015. Diachronic Semantics. Annual Review of Linguistics 1: 179-197.

Evans, V. 2004. Applying cognitive linguistics to pedagogical grammar: The case of over. In M. Achard and S. Niemeier (Eds.) Cognitive Linguistics, Second Language Acquisition, and Foreign Language Teaching. Berlin: De Gruyter Mouton. pp. 257-280.

Evans, V. 2006. Lexical concepts, cognitive models and meaning-construction. Cognitive Linguistics 17(4): 491-534.

Evans, V. 2015. A unified account of polysemy within LCCM theory. Lingua 157: 100-123.

Evans, V. and M. Green. 2006. Cognitive linguistics: an introduction. Edinburgh: Edinburgh University Press.

Evans, V. and A. Tyler. 2004. Rethinking English 'prepositions of movement': The case of to and through. Belgium Journal of Linguistics 18(1): 247-270.

Falkum, I. and A. Vicente. 2015. Polysemy: current perspectives and approaches. Lingua 157: $1-16$.

Fischer, K. 2010. Quantitative methods in cognitive semantics. Introduction to the volume. In D. Glyn and K. Fischer (Eds.) Quantiative Methods in Cognitive Semantics: Corpus-Driven Approaches. Berlin: De Gruyter Mouton. pp. 43-59.

Geeraerts, D. 2010. Theories of Lexical Semantics. Oxford: Oxford University Press.

Gibbs, R. 1994. Poetics of Mind. Figurative Thought, Language and Understanding. Cambridge: Cambridge University Press.

Gilquin, G. 2006. The place of prototypicality in corpus linguistics". In S. Gries and A. Stefanowitsch (Eds.) Corpora in Cognitive Linguistics. Berlin: Mouton de Gruyter. pp. 159-191.

Givón, T. 1985. Iconicity, isomorphism, and non-arbitrary coding in syntax. In J. Heiman (Ed.) Iconicity in Syntax. Amsterdam: John Benjamins. pp. 187-219.

Givón, T. 2000. Internal reconstruction: as method, as theory. In S. Gildea (Ed.) Reconstructing Grammar: Comparative Linguistics and Grammaticalization. Amsterdam: John Benjamins. pp. 107-159. 
Glyn, D. 2010. Corpus-driven cognitive semantics introduction to the field. In D. Glyn and K. Fischer (Eds.) Quantiative Methods in Cognitive Semantics: Corpus-Driven Approaches. Berlin: De Gruyter Mouton. pp. 1-41.

Glyn, D. and K. Fischer. (Eds.). 2010. Quantiative Methods in Cognitive Semantics: CorpusDriven Approaches. Berlin: De Gruyter Mouton.

Gries, S. 2006. Corpus-based methods and cognitive semantics. In S. Gries and A. Stefanowitsch (Eds.) Corpora in Cognitive Linguistics. Berlin: Mouton de Gruyter. pp. 57-99.

Gries, S. and D. Divjak. 2010. Quantitative approaches in usage-based cognitive semantics: myths, erroneous assumptions, and a proposal. In D. Glyn and K. Fischer (Eds.) Quantiative Methods in Cognitive Semantics: Corpus-Driven Approaches. Berlin: De Gruyter Mouton. pp. 333-353.

Gries S. and A. Stefanowitsch. (Eds.) 2006. Corpora in Cognitive Linguistics. Berlin: Mouton de Gruyter.

Haspelmath, M. 1997. Indefinite pronouns. Oxford: Clarendon.

Haspelmath, M. 2003. The geometry of grammatical meaning semantic maps and crosslinguistic comparison. In M. Tomasello (Ed.) The New Psychology of Language. Mahwah: Lawrence Erlbaum Associates. pp. 211-242.

Haspelmath, M. 2004. Coordinating constructions: an overview. In M Haspelmath (Ed.) Coordinating Constructions. Amsterdam: John Benjamins. pp. 3-39.

Heine, B. 1997. Cognitive Foundations of Grammar. Oxford: Oxford University Press.

Heine, B., U. Claudi and F. Hünnemeyer. 1991. Grammaticalization. A Conceptual Framework. Chicago: University of Chicago Press.

Heine, B. and T. Kuteva. 2007. The Genesis of Grammar: A Reconstruction. Oxford: Oxford University Press.

Hopper, P. and E. Traugott. 2003. Grammaticalization. Cambridge: Cambridge University Press.

Ibarretxe-Antuñano, I. 1999. Metaphorical mapping in the sense of smell. In W. Gibbs and G. Steen (Eds.) Metaphor in Cognitive Linguistics. Amsterdam: John Benjamins. pp. 29-45.

Janssen, T. 2003. Monosemy versus polysemy. In H. Cuyckens, R. Dirven and J. Taylor (Eds.) Cognitive Approaches to Lexical Semantics. Berlin: Mouton de Gruyter. pp. 93-122.

Kiparsky, P. 2002. Event Structure and the Perfect. In D. Beaver, L. Casillas Martínez, B. Clark, and S. Kaufmann (Eds.) The Construction of Meaning. Stanford: CSLI Publications. pp. 1-20.

Lakoff, G. 1987. Women, Fire and Dangerous Things. Chicago: University of Chicago Press. 
Langacker, R. 1987. Foundations of Cognitive Grammar. Vol. 1. Theoretical prerequisites. Stanford: Stanford University Press.

Langacker, R. 1988. A usage-based model. In B. Rudzka-Ostyn (Ed.) Topics in Cognitive Linguistics. Amsterdam: John Benjamins. pp.127-161.

Langacker, R. 2007. Cognitive Grammar. In D. Geeraerts and H. Cuyckens (Eds.) The Oxford Handbook of Cognitive Linguistics. Oxford: Oxford University Press. pp. 421-462.

Langacker, R. 2011. Grammaticalization and Cognitive Grammar. In H. Narrog and B. Heine (Eds.) The Oxford Handbook of Grammaticalization. Oxford: Oxford University Press. pp. 79-91.

Lewandowska-Tomaszczyk, B. 2007. Polysemy, Prototypes, and Radical Categories. In D. Geeraerts and H. Cuyckens (Eds.) Handbook of Cognitive Linguistics. Oxford: Oxford University Press. pp. 139-169.

Lichtenberk, F. 1991. On the gradualness of grammaticalization. In E. Traugott and B. Heine (Eds.) Approaches to Grammaticalization. Vol.1. Amsterdam: John Benjamins. pp. 37-80.

Macnick, S. and S. Martinez-Conde. 2010. Sleights of Mind. What the Neuroscience of Magic Reveals about our Everyday Deceptions. New York: Henry Holt.

Maslov, J. 1988. Resultative, Perfect and Aspect. In V. Nedjalkov (Ed.) Typology of resultative constructions. Amsterdam: John Benjamins. pp. 63-85.

Massip-Bonet, À. 2013. Languages as a complex adaptive system: Towards an integrative linguistics. In À. Massip-Bonet and A. Bastardas-Boada (Eds.) Complexity Perspectives on Language, Communication and Society. Heidelberg: Springer. pp. 35-60.

Matlin, M. 2005. Cognition. Hoboken: Wiley.

Moravcsik, E. 2013. Introducing Language Typology. Cambridge: Cambridge University Press.

Munné, F. 2013. The Fuzzy Complexity of Language. In À. Massip-Bonet and A. BastardasBoada (Eds.) Complexity Perspectives on Language, Communication and Society. Heidelberg: Springer. pp. 175-196.

Narrog, H. 2010. A diachronic dimension in maps of case functions. Linguistic Discovery 8(1): $233-254$.

Narrog, H. and J. van der Auwera. 2011. Grammaticalization and semantic maps. In H. Narrog and B. Heine (Eds.) The Oxford Handbook of Grammaticalization. Oxford: Oxford University Press. pp. 318-327.

Nedjalkov, V. (Ed.) 1988. Typology of resultative constructions, Amsterdam: John Benjamins. 
Nedjalkov, V. 2001. Resultative constructions. In M. Haspelmath et al. (Eds.) Language Typology and Language Universals: An International Handbook. Vol. 2. Berlin: Walter de Gruyter. pp. 928-940.

Nikiforidou, K. 2009. Constructional analysis. In F. Brisard, J-O. Östman and J. Verschueren (Eds.) Grammar, Meaning and Pragmatics. Amsterdam: John Benjamins. pp. 16-32.

Nurse, D. 2008. Tense and Aspect in Bantu. Oxford: Oxford University Press.

Panther, K.U. and G. Radden. (Eds.) 1999. Metonymy in Language and Thought. Amsterdam: John Benjamins.

Perel'muter, I. 1988. The Stative, Resultative, Passive and Perfect in Ancient Greek (Homeric Greek). In V. Nedjalkov (Ed.) Typology of Resultative Constructions. Amsterdam: John Benjamins. pp. 277-287.

Radden, G. and Z. Kövecses. 1999. Towards a theory of metonymy. In K-U. Panther and G. Radden (Eds.) Metonymy in Language and Thought. Amsterdam: John Benjamins. pp. 17-59.

Raiziene, S. and B. Grigaite. 2005. Developing Child's Thinking Skills by Semantic Mapping Strategoies. Trames 9(2):192-206.

Sadler, M. 2007. Grammar in Use across Time and Space: deconstructing the Japanese "dative subject" Construction. Amsterdam: John Benjamins.

Sansò, A. 2010. How Conceptual Are Semantic Maps? Lingiustic Discovery 8(1): 288-309.

Steen, G. 2007. Finding Metaphor in Grammar and Usage. Amsterdam: John Benjamins.

Sweetser, E. 1990. From Etymology to Pragmatics: Metaphorical and Cultural Aspects of Semantic Structure. Cambridge: Cambridge University Press.

Taylor, J. 1989. Linguistic Categorization: Prototypes in Linguistic Theory. Oxford: Clarendon Press.

Taylor, J. 2002. Cognitive Grammar. Oxford: Oxford University Press.

Taylor, J. 2006. Polysemy and the lexicon. In G. Kristiansen, M. Achard, R. Dirven and F.J. Ruiz de Mendoza Ibáñez (Eds.) Cognitive Linguistics: Current Applications and Future Perspectives. Berlin: De Gruyter Mouton. pp. 51-80.

Traugott, E. 2001. Legitimate counterexamples to unidirectionality. Talk at Freiburg University, 17 October 2001.

Traugott, E. and E. König. 1991. The semantics-pragmatics of grammaticalization revisited. In E. Traugott and B. Heine (Eds.) Approaches to Grammaticalization. Vol. 1. Amsterdam: John Benjamins. pp. 189-218. 
Trivers, R. 2011. The Folly of Fools: The Logic of Deceit and Self-Deception in Human Life. New York: Basic Books.

Tuggy, D. 2003. The Nawatl verb kìsa: A case study in polysemy. In H. Cuyckens, R. Dirven and J. Taylor (Eds.) Cognitive Approaches to Lexical Semantics. Berlin: Mouton de Gruyter. pp. 323-362.

Tyler, A. and V. Evans. 2001. Reconsidering prepositional polysemy networks: The case of over. Language 77(4): 724-765.

Tyler, A. and V. Evans. 2003. The Semantics of English Prepositions: Spatial Scenes, Embodied Meaning, and Cognition. Cambridge: Cambridge University Press.

Van der Auwera, J. 2008. In defense of classical semantic maps. Theoretical Linguistics 34(1): 39-46.

Van der Auwera, J. and V. Gast. 2011. Categories and prototypes. In J.J. Song (Ed.) The Oxford Handbook of Typology. Oxford: Blackwell. pp. 166-189

Wade, C. and C. Tavris. 2012. Invitation to Psychology. Boston: Prentice Hall

Yu, N. 2008. Metaphor from body and culture. In R. W. Gibbs. (Ed.) The Cambridge Book of Metaphor and Thought. Cambridge: Cambridge University Press. pp. 247-261.

Yu, N. 2009. From Body to Meaning in Culture: Papers on Cognitive Semantic Studies of Chinese. Amsterdam: John Benjamins.

Zwarts, J. 2010. Semantic Map Geometry: Two Approaches. Linguistic Discovery 8(1): 377-395. 